\title{
RESÍDUOS DE ACETAMIPRID E THIAMETHOXAM EM TOMATE ESTAQUEADO (Lycopersicon esculentum Mill.), EM DIFERENTES MODALIDADES DE APLICAÇÃO
}

\author{
MILENA MARTINS DE OLIVEIRA PESSINI
}

Dissertação apresentada à Escola Superior de Agricultura "Luiz de Queiroz", Universidade de São Paulo, para obtenção do título de Mestre em Ciências, Área de Concentração: Entomologia.

PIRACICABA

Estado de São Paulo - Brasil

Abril - 2003 


\title{
RESÍDUOS DE ACETAMIPRID E THIAMETHOXAM EM TOMATE ESTAQUEADO (Lycopersicon esculentum Mill.), EM DIFERENTES MODALIDADES DE APLICAÇÃO
}

\author{
MILENA MARTINS DE OLIVEIRA PESSINI
}

Engenheiro Agrônomo

Orientador: Prof. Dr. OCTAVIO NAKANO

Dissertação apresentada à Escola Superior de Agricultura "Luiz de Queiroz", Universidade de São Paulo, para obtenção do título de Mestre em Ciências, Área de Concentração: Entomologia.

PIRACICABA

Estado de São Paulo - Brasil

Abril - 2003 
Dados Internacionais de Catalogação na Publicação (CIP) DIVISÃO DE BIBLIOTECA E DOCUMENTAÇÃO - ESALQ/USP

\author{
Pessini, Milena Martins de Oliveira \\ Resíduos de Acetamiprid e Thiamethoxam em tomate estaqueado \\ (Lyc opersic on esc ulentum Mill.), em diferentes moda lidades de \\ a plicação / Milena Martins de O liveira Pessini. - - Piracicaba, 2003. \\ $71 \mathrm{p}$. \\ Dissertação (mestrado) - - Escola Superior de Agricultura Luiz de \\ Queiroz, 2003. \\ Bibliografia. \\ 1. Controle químico 2. Estacas (pla ntas) 3. Impactosa mb ienta is 4. \\ Inseticidas [aplic ações] 5. Resíduos de pesticidasem plantas I. Título
}

CDD 635.642

"Permitida a cópia total ou parcial deste documento, desde que citada a fonte - O autor" 
Dedico e ofereço,

Aos meu pais, Antonio Luiz Pessini e Maria das Graças M. O. Pessini;

Às minhas irmãs, Mariana e Maíra,

Aos meus familiares,

E ao querido Victor. 


\section{AGRADECIMENTOS}

Ao Prof. Dr. Octavio Nakano, pela orientação, apoio, amizade e confiança.

Ao Técnico Agrícola Augusto César Pinheiro Florim, pelo auxílio, amizade e atenção.

Ao Dr. Luiz Roberto Pimentel Trevizan pela análise dos materiais e pelo apoio no trabalho.

Ao Departamento de Entomologia, Fitopatologia e Zoologia Agrícola da ESALQ/USP, pela oportunidade.

Aos Professores do curso de Pós-graduação do Departamento de Entomologia, Fitopatologia e Zoologia Agrícola da ESALQ/USP pelos ensinamentos.

À Coordenadoria de Aperfeiçoamento de Pessoal do Ensino Superior CAPES - e à Syngenta pela concessão de bolsas de estudo.

Ao Prof. Gilberto Casadei de Baptista pelo auxílio nos trabalhos. 
Aos colegas e estagiários do Setor de Defensivos do Departamento de Entomologia, Fitopatologia e Zoologia Agrícola da ESALQ/USP.

Aos funcionários do Laboratório de Resíduos de Pesticidas e do Departamento de Entomologia, Fitopatologia e Zoologia Agrícola da ESALQ/USP.

Aos funcionários da Biblioteca Central da ESALQ/USP.

A todas as pessoas que, direta ou indiretamente contribuíram para a realização desse trabalho, o meu muito obrigada.

E a Deus, por estar sempre comigo. 


\section{SUMÁRIO}

Página

LISTA DE FIGURAS..................................................................... ix

LISTA DE TABELAS......................................................................

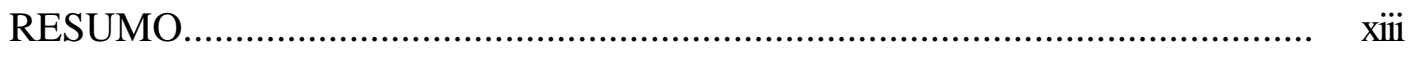

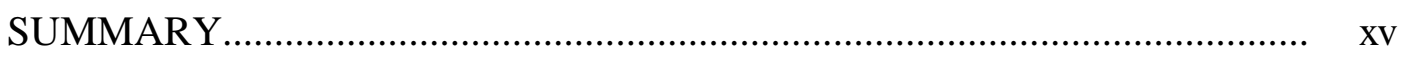

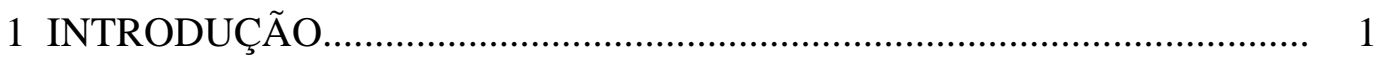

2 REVISÃO DE LITERATURA.................................................................. 4

2.1 A cultura do tomateiro........................................................................ 4

2.2 Controle químico na agricultura.............................................................. 6

2.3 Toxicidade dos pesticidas.................................................................... 7

2.4 Depósito, penetração e persistência de pesticidas....................................... 10

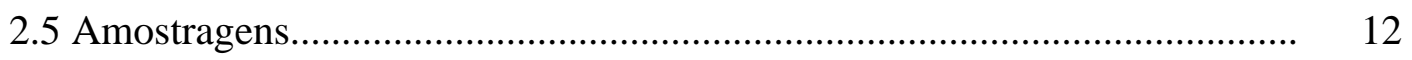

2.6 Revisão dos inseticidas utilizados no presente trabalho................................. 13

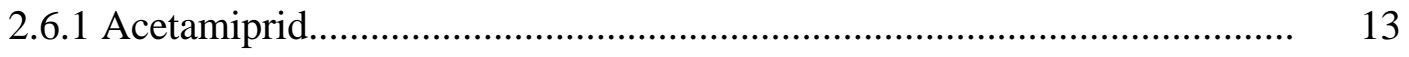

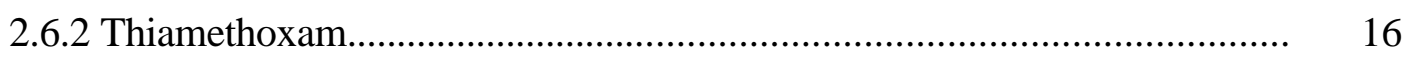

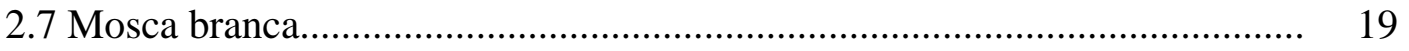

2.7.1 Histórico.......................................................................................... 19

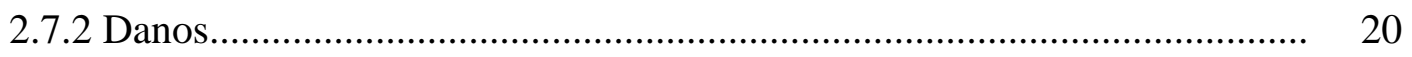

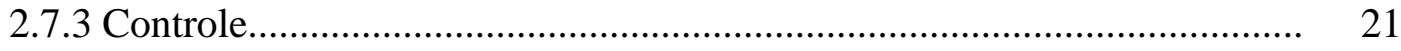

2.7.3.1 Controle químico........................................................................... 21

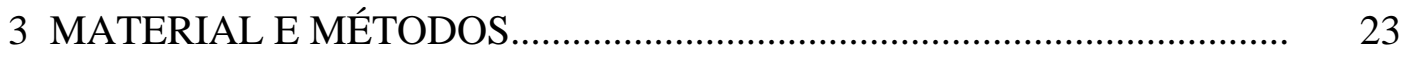

3.1 Caracterização e condução dos experimentos de campo.............................. 23

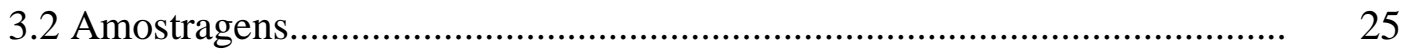


3.3 Avaliação de controle de pragas e sintomas de viroses............................... 25

3.4 Descrição do método de análise de resíduos de acetamiprid em frutos de

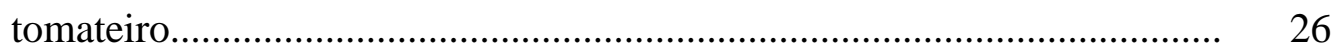

3.4.1 Princípio do método............................................................................... 26

3.4.2 Procedimento analítico....................................................................... 26

3.4.2.1 Aparelhos/ Equipamentos.................................................................. 26

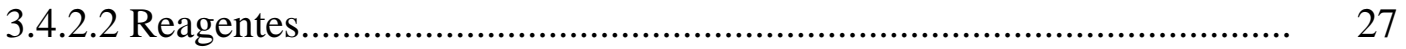

3.4.2.3 Vidrarias e outros materiais............................................................ 27

3.4.4 Marcha analítica.................................................................................. 28

3.4.4.1 Preparo das soluções padrão.............................................................. 28

3.4.4.2 Fortificações..................................................................................... 29

3.4.4.3 Extração...................................................................................... 29

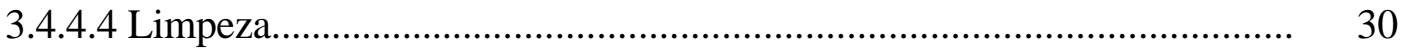

3.4.4.5 Determinação quantitativa................................................................. 31

3.4.4.6 Cálculo dos resíduos...................................................................... 32

3.5 Descrição do método de análise de resíduos de acetamiprid em folhas de

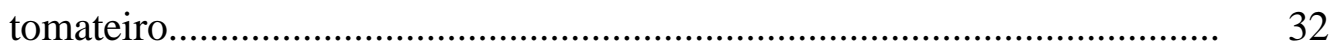

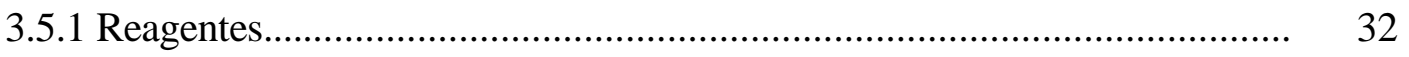

3.5.2 Aparelhos/ Equipamentos.................................................................... 33

3.5.3 Vidrarias e outros materiais.................................................................. 33

3.5.4 Marcha analítica..................................................................................... 33

3.6 Descrição do método de análise de resíduos de thiamethoxam em frutos de tomateiro.................................................................................... 33

3.6.1 Princípio do método........................................................................... 33

3.6.2 Procedimento analítico..................................................................... 34

3.6.2.1 Aparelhos/ Equipamentos.................................................................. 34

3.6.2.2 Solventes/ Reagentes.................................................................. 34

3.6.2.3 Vidrarias e outros materiais............................................................. 35

3.6.3 Marcha analítica................................................................................ 36

3.6.3.1 Preparo das soluções....................................................................... 36 
3.6.3.2 Fortificações...................................................................................... 36

3.6.3.3 Extração....................................................................................... 37

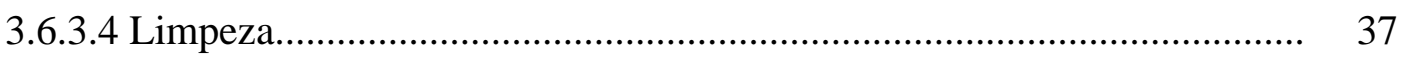

3.6.3.5 Determinação quantitativa......................................................................... 39

3.7 Análise dos dados............................................................................... 40

4 RESULTADOS E DISCUSSÃO............................................................... 41

4.1 Resíduos de acetamiprid em frutos - Experimento I........................................ 41

4.2 Resíduos de acetamiprid em folhas - Experimento I....................................... 42

4.3 Residuos de thiamthoxam em frutos - Experimento I.................................... 43

4.4 Resíduos de thiamethoxam em folhas - Experimento I................................... 44

4.5 Resíduos de acetamiprid em frutos - Experimento II...................................... 45

4.6 Resíduos de acetamiprid em folhas - Experimento II..................................... 46

4.7 Resíduos de thiamethoxam em frutos - Experimento II................................... 46

4.8 Residuos de thiamethoxam em folhas - Experimento II.................................. 47

4.9 Avaliação do controle de pragas..................................................................... 48

4.9.1 Experimento I.................................................................................. 48

4.9.2 Experimento II.............................................................................. 49

4.10 Quantidade de ingrediente ativo aplicado por hectare.................................. 55

4.10.1 Thiamethoxam ("band-aid")..................................................................... 55

4.10.2 Acetamiprid ("band-aid")...................................................................... 56

4.10.3 Thiamethoxam (sachê)........................................................................... 56

4.10.4 Acetamiprid (sachê) ............................................................................. 57

4.10.5 Thiamethoxam (pulverização).................................................................... 57

4.10.6 Acetamiprid (pulverização)...................................................................... 57

4.10.7 Correlação entre a quantidade de ingrediente ativo e porcentagem de eficiência.................................................................................... 58

4.11 Avaliação de sintomas de viroses............................................................... 59

4.12 Vantagens das aplicações nas formas de "band-aid" e sachê....................... 59

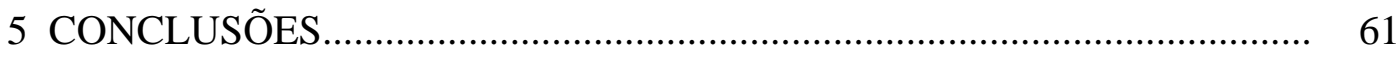

REFERÊNCIAS BIBLIOGRÁFICAS......................................................... 62 


\section{LISTA DE FIGURAS}

Página

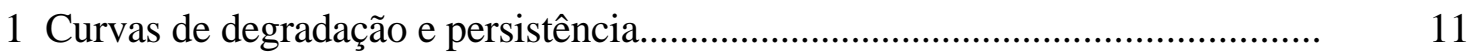

2 Fórmula estrutural do acetamiprid................................................................. 14

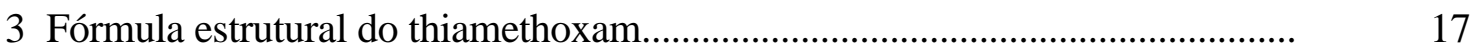

4 Eficiência dos tratamentos visando o controle da mosca branca na cultura do tomate, em todas as avaliações realizadas durante $\mathrm{o}$

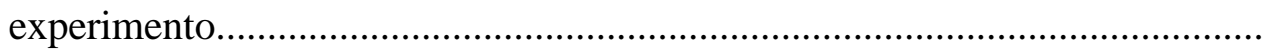




\section{LISTA DE TABELAS}

Página

1 Posição ordinária dos principais produtores de tomate no Brasil e no mundo....

2 Classificação de defensivos quanto à toxicidade.

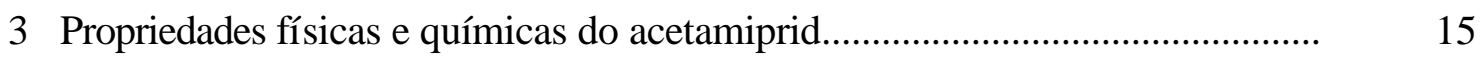

4 Propriedades toxicológicas e ecotoxicológicas do acetamiprid.............................. 16

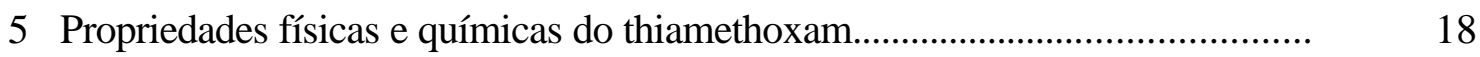

6 Resíduos de acetamiprid em frutos de tomate (Experimento I)............................. 41

7 Resíduos de acetamiprid em folhas de tomate (Experimento I)............................ 42

8 Resíduos de thiamethoxam e seu metabólito CGA 322704, em frutos de tomate (Experimento I) .......................................................................... 43

9 Resíduos de thiamethoxam e seu metabólito CGA 322704 em folhas de

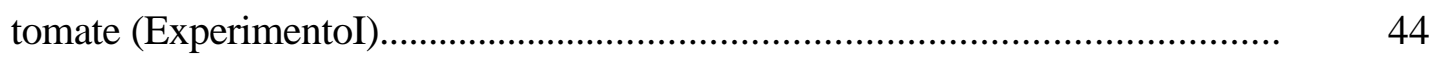


10 Resíduos de acetamiprid em frutos de tomate (Experimento II)

11 Resíduos de acetamiprid em folhas de tomate (Experimento II)

12 Resíduos de thiamethoxam e seu metabólito CGA 322704, em frutos de tomate (Experimento II)

13 Resíduos de thiamethoxam e seu metabólito CGA 322704 em folhas de tomate (Experimento II)

14 Número médio de adultos e ninfas de mosca branca vivas, por tratamento, porcentagem de eficiência, 25 dias após o transplante das mudas de tomate. Piracicaba, 2002

15 Número médio de adultos e ninfas de mosca branca vivas, por tratamento, porcentagem de eficiência, 32 dias após o transplante das mudas de tomate. Piracicaba, 2002

16 Número médio de adultos e ninfas de mosca branca vivas, por tratamento, porcentagem de eficiência, 40 dias após o transplante das mudas de tomate. Piracicaba, 2002

17 Número médio de adultos e ninfas de mosca branca vivas, por tratamento, porcentagem de eficiência, 43 dias após o transplante das mudas de tomate. Piracicaba, 2002 
18 Número médio de adultos e ninfas de mosca branca vivas, por tratamento, porcentagem de eficiência, 54 dias após o transplante das mudas de tomate.

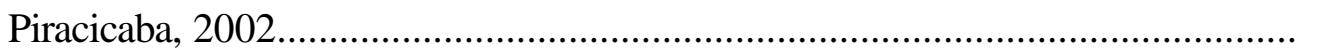

19 Correlação entre as quantidades de ingrediente ativo por tratamento e suas respectivas porcentagens de eficiência, média dos 32 e 43 dias após o

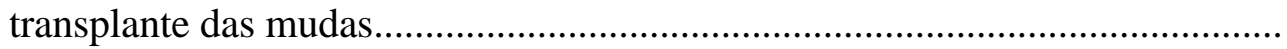




\title{
RESÍDUOS DE ACETAMIPRID E THIAMETHOXAM EM TOMATE ESTAQUEADO (Lycopersicon esculentum Mill.), EM DIFERENTES MODALIDADES DE APLICAÇÃO
}

\author{
Autora: MILENA MARTINS DE OLIVEIRA PESSINI \\ Orientador: Prof. Dr. OCTAVIO NAKANO
}

\section{RESUMO}

No final dos anos 80, intensificaram-se as preocupações com os danos provocados à saúde do trabalhador rural $\mathrm{e}$ ao meio ambiente devido o uso indiscriminado de agrotóxicos. A descoberta de novos grupos de inseticidas, menos tóxicos e agressivos ao meio ambiente, vieram amenizar o problema. Entretanto, seus efeitos residuais ainda são pouco estudados, o que motivou esta pesquisa. Este trabalho visou avaliar o efeito dos inseticidas acetamiprid e thiamethoxam, pertencentes ao grupo dos neonicotinóides em diferentes modalidades de aplicação, com a finalidade de reduzir o número de pulverizações na cultura do tomate, eliminando seus efeitos negativos sobre o meio ambiente, bem como evitar a contaminação desse inseticida sobre os aplicadores. O ensaio foi realizado no campo experimental de tomate envarado no Departamento de Entomologia, Fitopatologia e Zoologia da ESALQ/USP, utilizando o cultivar Santa Clara, sendo realizados três tipos de aplicações: a) "band-aid", que consistiu em misturar 
os inseticidas a um gel seco, colocando-se estes produtos em um saquinho de papel e envolvendo-os a uma fita adesiva, sendo colocados no colo das plantas; b) sachê, onde os inseticidas foram misturados com o gel seco e acondicionados em sachês, sendo colocados junto à raiz das mudas por ocasião do plantio; c) convencional, onde os inseticidas foram pulverizados com aplicador manual costal. A análise dos resíduos em frutos e folhas foi realizada por técnica de cromatografia líquida (HPLC) e, como resultado, constatou-se que: em tratamentos onde acetamiprid foi aplicado, todos apresentaram resíduos abaixo do mínimo detectável pela técnica HPLC; e, em tratamentos com thiamethoxam, somente em folhas onde o produto foi aplicado na forma de sachê e pulverização, foram observados resíduos, 0,06 e 0,3 mg/kg, respectivamente. O LMR (limite máximo de resíduo) para acetamiprid e thiamethoxam em frutos de tomate é de 0,5 e $0,02 \mathrm{mg} / \mathrm{kg}$, respectivamente. Das análises realizadas, não detectou-se resíduos nos frutos analisados, somente sendo encontrados nas folhas. Pôdese concluir que os métodos de aplicação analisados não apresentam problemas quanto à toxicidade ao meio ambiente e trabalhadores e resíduos. A área apresentou infestação de mosca branca, o que possibilitou a avaliação de controle da praga pelos produtos testados, nas diferentes modalidades de aplicação. Nos tratamentos onde acetamiprid e thiamethoxam foram aplicados em pulverização, o controle foi satisfatório. Quando aplicados na forma de sachê e "band-aid", o controle foi menos satisfatório, porém, com a vantagem de não poluir o meio ambiente, bem como o evitar exposição do aplicador e dos inimigos naturais aos produtos. 


\title{
ACETAMIPRID AND HIAMETHOXAM RESIDUES IN STAKED TOMATO CROP (Lycopersicon esculentum Mill.) FROM DIFFERENT KINDS OF APPLICATION
}

\author{
Author: MILENA MARTINS DE OLIVEIRA PESSINI \\ Adviser: Prof. Dr. OCTAVIO NAKANO
}

\section{SUMMARY}

In the end of 80's, careful was enhanced by rural worker health and environmental damages because of pesticides indiscriminated applications. The development of new insecticides groups, less toxic and aggressive to environment came to minimize the problem. However, their residue effects are not studied as it must be, and this was the reason of this research. This work aimed to evaluate the effect of the neonicotinoid insecticides acetamiprid and thiamethoxam, from different application methods, aiming to study the possibility of decreasing the number of sprays on tomato crop, removing their negative effects on environment, and avoid rural workers contamination. This trial was carried out on staked tomato crop in the Department of Entomology, Phytopathology and Zoology of ESALQ/USP, using Santa Clara tomato cultivar in three application methods: a) "band-aid", that consisted in mix the insecticides with a dry gel, placed them into a little paper bag, wrapped up witn an adhesive tape and arranged it on the plant's neck; b) "sachet", where insecticides were mixed with a dry gel and placed into a little paper bag, and they were arranged with the plant roots during the planting; c) conventional, where the insecticides were sprayed 
with a back sprayer. Residue analyses of tomato fruits and leaves were done by HPLC technique, and the results were: all treatments where acetamiprid were applied showed residue levels lower than the minimum detectable by HPLC technique; treatments with thiamethoxam, residues were observed only in leaves, when applied in "sachet" and conventional methods, at 0.06 and $0.3 \mathrm{mg} / \mathrm{kg}$, respectively. The official tolerance to acetamiprid and thiamethoxam in tomato fruits are 0.5 and $0.02 \mathrm{mg} / \mathrm{kg}$, respectively. The analyses, residues showed non detectable in fruits. The application techniques checked did not rise problems with environmental and rural workers based in their toxicities and residues. The experimental field showed whitefly infestation, and made possible control evaluation of this pest by the tested products, from different application methods. Treatments where acetamiprid and thiamethoxam were applied in conventional method, showed better pest control. When applied on "sachet" and "band-aid" methods, control was satisfactory; however, these methods have the advantage of lower environment polution, rural worker exposition to products and preservation of natural enemies mortality. 


\section{INTRODUÇÃO}

O tomate é hoje, provavelmente, a hortaliça mais conhecida e de maior consumo no mundo, devido à multiplicidade de seu aproveitamento na alimentação humana, fresco ou conservado, à sua bonita apresentação, ao seu aroma e sabor característico.

O Brasil é um dos principais produtores mundiais e o Estado de São Paulo contribui com cerca de $30 \%$ desta produção. De acordo com as estimativas de safra do Instituto Brasileiro de Geografia e Estatística - IBGE, em 1996 o Estado de São Paulo produziu 370.000 toneladas (IBGE, 2000). São muitas as espécies cultivadas e consumidas pelos brasileiros. Sem dúvida nenhuma, o tomate tem um destaque todo especial (Maranca, 1981).

A cultura do tomate é uma das mais difíceis de se conduzir para se ter um resultado satisfatório. A produção é feita a custos elevadíssimos devido à necessidade de altas dosagens de adubos, irrigações constantes, controle semanal de pragas e doenças, manutenção da lavoura sem outros concorrentes, etc.

O aumento de produção de tomate está sendo feito pela ampliação de novas áreas. O crescimento pela expansão da área de cultivo não é a solução ideal para a Agricultura Moderna, pois os solos bons para a cultura e próximos aos mercados consumidores são limitados. Em consequência, há a necessidade de se elevar o rendimento da cultura através de variedades melhoradas, sementes de boa qualidade, nutrição e suprimento de água feitas de modo correto, controle eficiente de pragas e doenças, etc.

No final dos anos oitenta, intensificaram-se as preocupações com os danos provocados à saúde do trabalhador rural devido ao uso indiscriminado de agrotóxicos. 
Os consumidores também tornaram-se mais exigentes em qualidade e segurança dos alimentos ingeridos.

Esta nova tendência de mercado exige do horticultor disciplina na aplicação de agrotóxicos. Aspectos quantitativos e qualitativos deverão ser observados, como o respeito ao período de carência dos inseticidas, a utilização de produtos seletivos e a adoção de técnicas de controle fitossanitárias que diminuam os resíduos de agrotóxicos nos alimentos. Os produtos de melhor qualidade têm sido diferenciados no mercado através de selos de certificação, fornecidos por órgãos oficiais de fiscalização, que atestam os métodos de produção e a qualidade do produto fornecido.

A rapidez de ação, facilidade de uso, economicidade e eficiência dos produtos químicos aparentemente constituíram-se na solução de inúmeros problemas agrícolas, fazendo com que houvesse um incremento substancial na produção e consumo de pesticidas nas últimas décadas, tornando o Brasil o terceiro mercado mundial desses insumos, com valor estimado de US\$ 2.346 bilhões, em 1999. Entretanto, essa grande utilização, muitas vezes de forma inadequada, pode eventualmente trazer problemas de saúde pública, com grande número de intoxicações.

Os pesticidas podem permanecer nos alimentos por via direta, como resultado da aplicação numa das fases de sua produção, armazenamento ou transporte, ou indireta, como no caso dos animais tratados com ração composta de vegetais contaminados, na rotação de culturas, quando o solo conserva resíduos de aplicações anteriores e os transmite às novas culturas, em água contaminadas, etc. (Lara, 1986).

Por ser uma hortaliça muito exigente em tratos fitossanitários, pelo fato de estar sujeita ao ataque de grande número de pragas e doenças e, mais de um terço da produção nacional dessa solanácea destinar-se à industrialização, sendo grande parcela exportada em forma de suco, purê ou extrato, é fundamental que os níveis de resíduos de pesticidas encontrados nesses produtos obedeçam aos limites de tolerância estabelecidos pela legislação e aos internacionalmente aceitos.

Devido à necessidade de um melhor manejo da utilização dos inseticidas - por serem mais tóxicos dentro do grupo dos defensivos nesta cultura - realizou-se a presente pesquisa, que teve como objetivos: 
a) avaliar o efeito residual dos inseticidas nas diferentes modalidades de aplicação, através da ocorrência de pragas;

b) determinar os resíduos dos inseticidas em folhas e frutos de tomate estaqueado, nessas diferentes modalidades de aplicação;

c) correlacionar os níveis residuais encontrados com o limite máximo de resíduos LMR (tolerância). 


\section{REVISÃO DE LITERATURA}

\subsection{A cultura do tomateiro}

O tomate, Lycopersicon esculentum Mill., é originário da América do Sul, do Equador, do Norte do Chile (Jenkins, 1948), e das Ilhas Galápagos. Espalhou-se pelas Américas através de índios e viajantes europeus do século XV (Rick, 1967).

Pertence à ordem Tubiflorae, família Solanaceae, sendo considerada uma planta autógama. As flores são hermafroditas, pequenas e amarelas, se dispõem em pencas. Os frutos são carnosos e podem ser vermelhos, amarelos ou cor-de-rosa, dependendo da variedade (Minami \& Haag, 1989).

A cultura do tomateiro é de grande importância econômica e social no Brasil e em todo o mundo, sendo a base de sustentação de diversos agricultores. Apresenta muitos destinos e várias maneiras de consumo, principalmente "in natura" (Barbosa \& França, 1980; Folquer, 1976; Rodriguez et al., 1997; Villareal, 1982). A Tabela 1 apresenta os principais produtores de tomate no Brasil e no mundo. 
Tabela 1. Posição ordinária dos principais produtores de tomate no Brasil e no mundo.

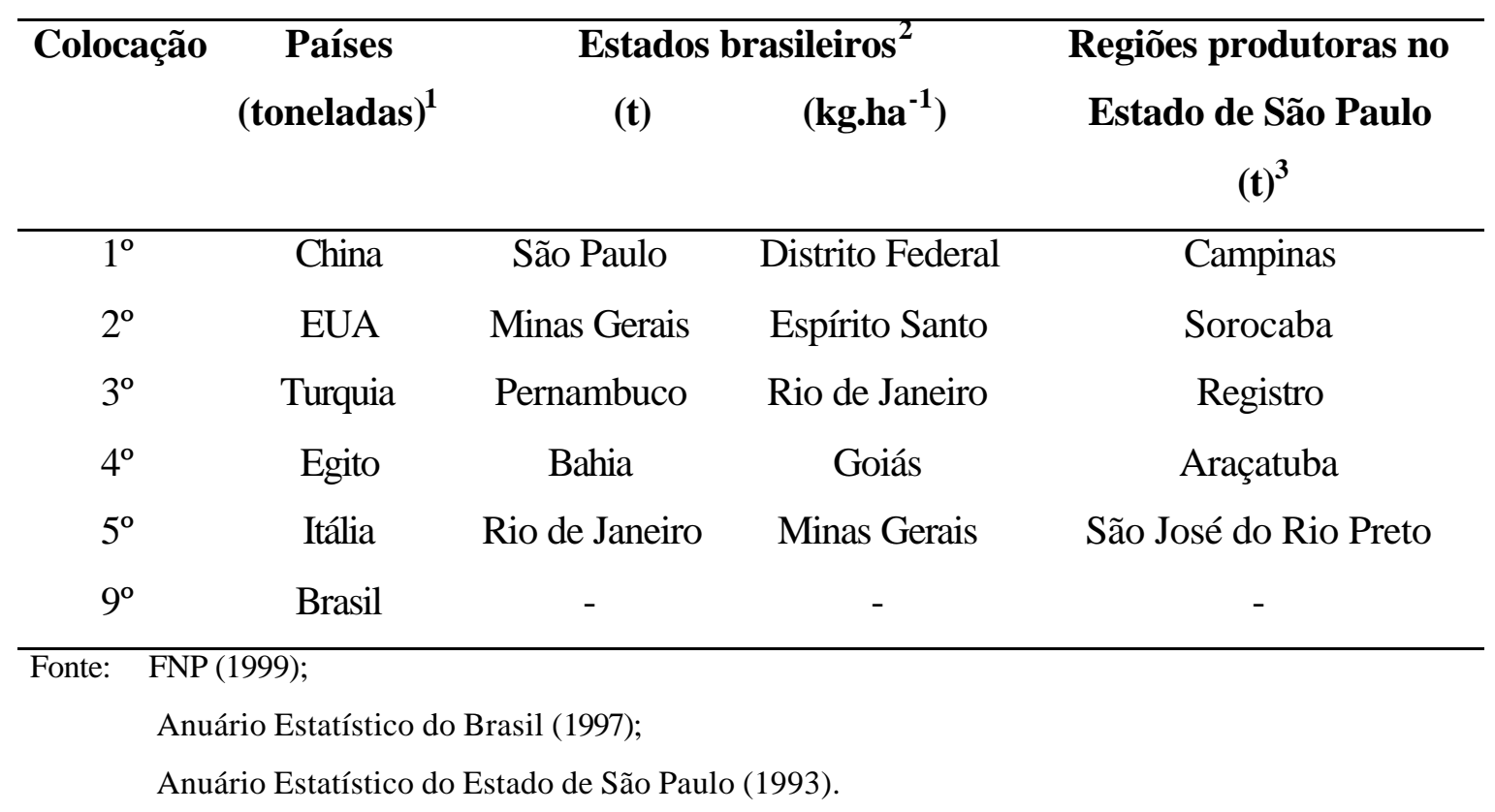

De acordo com o Anuário Estatístico do Brasil (1998), a área plantada foi de 62.054 ha, com produção obtida de $2.715 .016 \mathrm{t}$ e um rendimento de $43.752 \mathrm{~kg} \cdot \mathrm{ha}^{-1}$. Só no Estado de São Paulo, a área plantada foi de 15.950 ha, com produção obtida de 805.235 t e em rendimento de $50.485 \mathrm{~kg} \cdot \mathrm{ha}^{-1}$ (Anuário Estatístico do Estado de São Paulo, 1995).

Esta cultura é uma das mais difíceis de se conduzir em campo aberto, pois é afetada por insetos, ácaros, doenças fúngicas, fitobacterioses, fitoviroses e fitonematoses (Atherton \& Rudich, 1986; Latorre et al., 1990; Minami, 1983; Minami \& Haag, 1989; Silva et al., 1998). Devido a isto, muitos defensivos são empregados no cultivo desta solanácea.

O controle químico das pragas tem sido o mais disponível ao tomaticultor. Nakano (1999) citou diversas razões pela qual o controle químico tem sido predominante em hortaliças, entre elas, a especificidade dos agentes de controle biológico e o ciclo curto das culturas, que impede o estabelecimento de predadores e 
parasitóides. A necessidade do uso de fungicidas, bactericidas e adubos foliares, exige pulverização com pressão elevada, e isso impede o estabelecimento de inimigos naturais, constituídos por frágeis microhimenópteros.

\subsection{Controle químico na agricultura}

Os defensivos agrícolas são introduzidos no meio obedecendo critérios técnicos e têm por objetivo impedir a ação direta ou indireta de formas de vida animal ou vegetal prejudiciais à agricultura (insetos, ácaros, fungos, plantas daninhas, etc.) (Baptista, 1999).

A utilização de controle químico de pragas é um componente da cultura tecnológica da humanidade atual. $\mathrm{O}$ uso de agrotóxicos tem trazido benefícios reais, tais como: aumento na produção de alimentos e fibras, proteção dos produtos armazenados e proteção de milhões de pessoas através da prevenção de certas doenças (Freedman, 1989).

No que se refere às atividades agrícolas, sabe-se dos investimentos e trabalhos necessários ao processo de produção. A necessidade cada vez maior de alimentos induz a uma preocupação constante no sentido de garantir o abastecimento à população. Para isso, o controle das pragas que comprometem as plantas precisa ser feito com o uso de substâncias que possam assegurar essa produção (Nakano, 1985).

Em 1987, o Brasil era o maior mercado de defensivos agrícolas entre os países em desenvolvimento e o quinto do mundo, movimentando uma grande quantia no mercado financeiro e aplicando uma enorme quantidade de fungicidas, herbicidas e inseticidas no ambiente (Garcia, 1996).

Para que um produto químico possa ser adequadamente empregado, deve ser

plenamente conhecido quanto às suas vantagens e desvantagens. Normalmente, são relacionadas as seguintes vantagens do uso de defensivos: têm efeito rápido e geralmente são eficientes; são ágeis e fáceis de aplicar; são econômicos; de fácil aquisição; e não necessitam de planejamento com antecedência para serem usados. 
Porém, se usados de maneira incorreta, trazem desvantagens consideráveis, como: intoxicações em homens, animais domésticos e fauna silvestre; ocasionam presença de resíduos tóxicos em alimentos; podem reduzir a população de organismos benéficos; podem ocasionar ressurgência, resistência; e, contaminação do meio ambiente (Baptista, 1999).

O emprego correto de defensivos pode assegurar as colheitas contra o ataque de organismos nocivos à agricultura por tempo limitado. Porém, seu uso intensivo acarreta consequências imprevisíveis, tanto para mamíferos como para insetos, principalmente aqueles considerados úteis (Gallo et al., 1988).

Para um grupo da sociedade, o método de controle químico continuará a desempenhar papel importante nos programas de controle de pragas e doenças nas próximas décadas (Freedman, 1989; Raetano, 1991).

De acordo com a composição química, os pesticidas podem ser divididos em três grupos principais: compostos inorgânicos, compostos de origem vegetal, bacteriana e fúngica e compostos orgânicos sintéticos. $\mathrm{E}$, as principais classes de compostos sintéticos são: compostos organoclorados, compostos organofosforados, carbamatos, piretróides, nitroderivados de fenóis e novos inseticidas, que atuam nas sinapses periféricas e aqueles que não atuam no sistema nervoso, como os reguladores de crescimento, os que atuam na cadeia respiratória e os inseticidas microbianos (Baptista, 1999; Ferreira, 1995).

\subsection{Toxicidade dos pesticidas}

Devido à necessidade da utilização dos defensivos agrícolas como um dos meios de que dispomos atualmente para a obtenção de maiores e melhores produções em produtividade e qualidade, e para a proteção das colheitas obtidas, torna-se indispensável verificar, para cada defensivo, suas características toxicológicas.

O poder tóxico de um defensivo é determinado estabelecendo-se a dose mínima necessária para matar o inseto. Esta dose, por sua vez, é variável de acordo com os 
produtos, reações fisiológicas de cada organismo, etc. (Gallo et al., 1988; Nakano et al., 1992).

Segundo Baptista (1999) e Batista et al. (1992), os pesticidas, ou defensivos agrícolas, ou agrotóxicos, como substâncias químicas que são, podem ter ação fisiológica sobre os organismos vivos, e a importância de seu uso deve ser equilibrada pela informação dos efeitos que os mesmos podem causar em pessoas que manipulam os produtos nas fábricas e nos campos, nos consumidores de alimentos, nos animais domésticos e silvestres, além dos organismos aquáticos e no meio ambiente.

Do ponto de vista toxicológico, eles podem ser mais ou menos tóxicos ao homem, existindo para cada um o estudo da avaliação tóxica correspondente, feita tanto em países, como internacionalmente, esta feita pela FAO/OMS (Baptista, 1999). Esta toxicidade depende de uma série de fatores, como quantidade, exposição, tempo de ação, tipo do organismo, condições climáticas, etc.

A avaliação da toxicidade pode ser feita pela dose letal 50 , ou $\mathrm{DL}_{50}$, que geralmente é estudada em ratos albinos e outros animais de laboratório (Baptista et al., 1992), das quais uma das mais importantes é a aguda oral (quando a exposição se dá através de uma dose única e pela boca), havendo, ainda, a dérmica (quando a exposição ocorre pela pele) ou a inalatória (pelas vias respiratórias). E, a $\mathrm{DL}_{50}$ é definida como a dose que previsivelmente causará uma resposta de 50\% em uma população, na qual se procurará determinar o efeito letal, e sua unidade é mg/kg (Baptista, 1999). 
Tabela 2. Classificação de defensivos quanto à toxicidade.

\begin{tabular}{ccccc}
\hline $\begin{array}{c}\text { Classe } \\
\text { toxicológica }\end{array}$ & Categoria & $\begin{array}{c}\text { Cor da faixa } \\
\text { no rótulo }\end{array}$ & $\begin{array}{c}\text { DL50 }(\mathbf{m g} / \mathbf{k g}) \\
\text { (aguda ora) }\end{array}$ & $\begin{array}{c}\text { Dose letal para o } \\
\text { homem adulto }\end{array}$ \\
\hline I & $\begin{array}{c}\text { extremamente } \\
\text { tóxicos }\end{array}$ & vermelha & $<5$ & 1 pitada \\
II & muito tóxicos & amarela & 5 a 50 & 1 colher de chá \\
III & $\begin{array}{c}\text { moderadamente } \\
\text { tóxicos }\end{array}$ & azul & 50 a 500 & até 2 colheres de \\
& & & & sopa \\
IV & pouco tóxicos & verde & 500 a 5000 & até 2 copos \\
\hline
\end{tabular}

Fonte: Gallo et al. (1988)

Os defensivos agrícolas, mesmo bem aplicados, podem deixar resíduos tóxicos nos alimentos. Para todos os princípios ativos de defensivos, de uso autorizado no Brasil, existem as tolerâncias legais ou limites máximos de resíduos permitidos para cada cultura e para cada defensivo autorizado para ela (Baptista et al., 1992).

Para Martinez (1984), o limite máximo de resíduo (LMR), ou tolerância, corresponde à quantidade máxima de resíduos de defensivo tolerado no alimento, como decorrência de sua aplicação adequada, numa fase específica desde a sua produção até o consumo. É expressa em partes (peso) do defensivo e/ou seus derivados por um milhão de partes (em peso) do alimento (ppm) ou mg. $\mathrm{kg}^{-1}$.

Outro conceito toxicológico importante é o intervalo de segurança, ou período de carência, que é o intervalo de tempo - expresso em dias - entre a última aplicação do defensivo e a colheita ou comercialização do vegetal, abate ou ordenha do animal, a fim 
e que os resíduos estejam de acordo com os limites máximos permitidos (BRASIL, 1998).

\subsection{Depósito, penetração e persistência de pesticidas}

O emprego de determinado defensivo deve ser acompanhado de prévio conhecimento de seu comportamento no ambiente e no material tratado. Por outro lado, é inevitável a ocorrência de resíduos nas superfícies que receberam aplicação desse produto, mesmo que em quantidades pequenas. Rouchaud \& Meyer (1982) citam que os defensivos geralmente penetram nos tecidos da planta, mesmo que apenas nas camadas subcuticulares. E, também, que os produtos que não penetram nos tecidos, permanecem na superfície da planta, sendo fotodecompostos, perdendo-se por volatilização e lavagem pelas chuvas.

Para os defensivos agrícolas, a camada do produto fracamente aderida, recobrindo a superfície da planta, após a aplicação na parte aérea é denominada depósito, enquanto que o material sobre ou no interior do substrato, após o início da atuação dos processos de penetração e degradação do composto refere-se ao resíduo (Gunther, 1969). O depósito torna-se resíduo tão logo ele seja afetado por lavagem, conversões metabólicas ou outros processos de alteração que causem atenuação e degradação (Gallo et al., 1988).

A grandeza dos depósitos iniciais e consequentemente os níveis de resíduos finais são influenciados por vários fatores. Dupuis (1975) cita que a presença de resíduos em uma determinada amostra depende do tipo de produto utilizado, da estrutura e propriedades físico-químicas de cada produto, do tipo de aplicação, incluindo época, número de aplicações, tempo entre última aplicação e amostragem, formulação usada, condições climáticas e fisiologia da planta.

Ebeling (1963) divide os fatores envolvidos no desaparecimento dos resíduos em dois grupos. No primeiro, encontram-se aqueles comuns a todos os produtos: a planta tratada, a formulação do pesticida e os fatores que causam o desaparecimento rápido dos 
depósitos superficiais como chuva, umidade, vento, temperatura e luminosidade. No segundo grupo estão os fatores que dependem da natureza do produto, incluindo produto e decomposição química, sendo que muitos pesticidas podem penetrar nos tecidos da planta e serem metabolizados ou quimicamente alterados, afetando a quantidade e persistência dos resíduos.

Para Gunther (1969), o desaparecimento de um produto fitossanitário na natureza, aplicado em pulverização, pode ser separado em duas fases: uma fase de degradação, em que há o desaparecimento rápido do depósito inicial e uma fase de persistência, onde ocorre uma diminuição lenta no nível de resíduos existentes no substrato, pela ação de fatores atmosféricos e ataque metabólico. Pode-se visualizar o desaparecimento ideal de um defensivo agrícola na Figura 1.

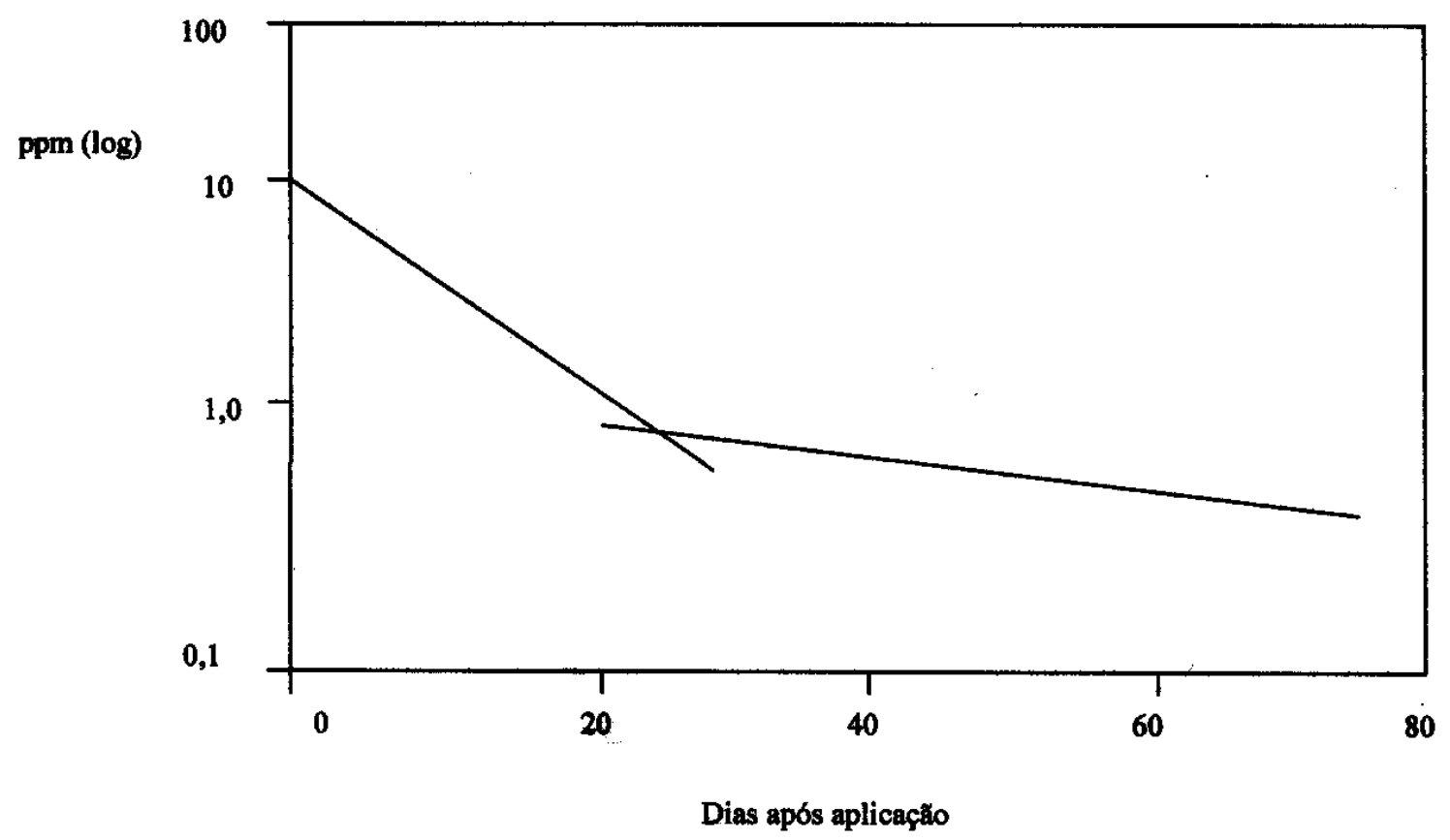

Figura 1 - Curvas de degradação (A) e de persistência (B). 
Quanto à penetração dos produtos, Gallo et al. (1988) citam três categorias de resíduos: resíduos extracuticulares, aderentes à camada de cera da cutícula; resíduos cuticulares, que estão incrustrados ou dissolvidos na camada de cera; e resíduos subcuticulares, penetrados abaixo dela. Os depósitos podem ser facilmente removidos por lavagens. Já os resíduos cuticulares podem ser removidos por lavagem e raspagem. Resíduos subcuticulares não podem ser eliminados ou mesmo diminuídos por meios mecânicos, exceto em poucos casos como descascando o fruto, onde a maior parte da penetração é restrita à casca.

Segundo Matsumara (1985), com os estudos de degradação e persistência de pesticidas pode-se determinar conceitos como o valor de meia vida de degradação (depósito) ou de persistência (resíduo), como sendo o tempo necessário para que metade de uma dada quantidade do material (depósito ou resíduo) se perca ou dissipe. Para um determinado composto, em uma dada cultura, a meia vida de persistência representa uma característica constante e um valor de referência em comparações de persistência de vários pesticidas em uma determinada cultura.

O resíduo presente em um produto, mesmo após a colheita, geralmente é reduzido por operações de processamento, podendo as informações a esse respeito serem úteis no estabelecimento de tolerâncias em alimentos processados e não processados (Baptista et al., 1992). Porém, Trevizan (1998) verificou que grãos de milho para pipoca, após o processamento, apresentaram resíduo superior ao grão antes do processamento.

\subsection{Amostragens}

As amostras coletadas para análise de resíduos devem ser representativas para que os resultados possam ser comparados (Martinez, 1984). 
Deve ser levado em consideração a escassez ou abundância de uma determinada cultura, o tamanho da unidade a ser colhida, assim como o número de plantas existentes em uma parcela (Lykken, 1963).

Nakano (1985) cita que a quantidade de frutos de tomate necessários para análise de resíduos é de $2 \mathrm{~kg}$, sem o cálice.

Rigitano (1982), coletou 20 frutos ao acaso por parcela, em função da amostragem, onde foi verificado a persistência de resíduos de metil paration e quinalfós em frutos de tomate.

Evaristo (1994) coletou 10 frutos ao acaso por parcela para a amostragem, onde foi estudado a persistência de resíduos deslocáveis de metamidofós em frutos de tomate.

Raetano et al. (1995) analisando resíduos de fentoato em tomate, coletou cerca de 15 frutos ao acaso, por parcela, em função da amostragem.

Para verificar a persistência de resíduos de fenitrotion em frutos e folhas de tomate, Pizano (1997) realizou a amostragem colhendo de 10 a 15 frutos maduros ou em início de maturação por parcela e, para amostragem de folhas, foi colhido aproximadamente $1 \mathrm{~kg}$ do material.

Baptista et al. (1995) analisando resíduos de zetacipermetrina em tomate, coletaram $1 \mathrm{~kg}$ de frutos ao acaso, por parcela, para amostragem.

Brioschi (2001) verificando resíduos de clorotalonil em frutos e folhas de tomate estaqueado, relatou que para a amostragem, coletou aproximadamente 15 frutos e aproximadamente $500 \mathrm{~g}$ de folhas por parcela. 


\subsection{Revisão dos inseticidas utilizados no presente trabalho}

\subsubsection{Acetamiprid}

Acetamiprid é um inseticida sistêmico, do grupo químico cloronicotinil, sendo seu nome químico

(E)-NI-[(6-chloro-3-pyrydil)-methyl]-N2-cyano-NImethylacetamidine, cuja fórmula estrutural está representada na Figura 2.

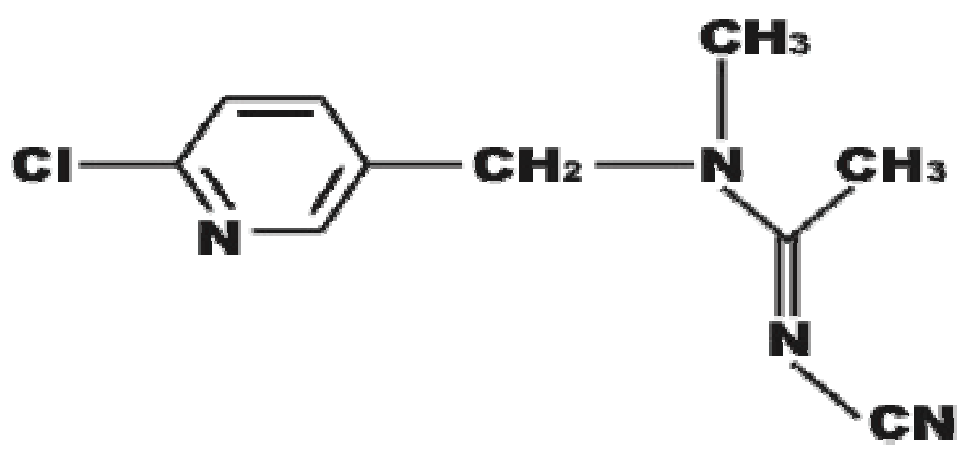

Figura 2 - Fórmula estrutural do acetamiprid.

De acordo com Tomlin (1994), o produto técnico se apresenta na forma de cristais incolores, de solubilidade em água a $25^{\circ} \mathrm{C}$ e $4200 \mathrm{mg} / \mathrm{L}$, solúvel em acetona, metanol, etanol, diclorometano, clorofórmio, acetonitrila e tetrahidrofurano. Tem estabilidade em soluções tamponadas com $\mathrm{pH} 4,5$, e 7, e degradado lentamente em $\mathrm{pH} 9$ e a $45^{\circ}$ C. É estável em luz solar. Suas propriedades físicas e químicas estão representadas na Tabela 3 . 
Tabela 3. Propriedades físicas e químicas do acetamiprid.

\begin{tabular}{cc}
\hline Parâmetros & Valores \\
\hline Fórmula química & $\mathrm{C}_{10} \mathrm{H}_{11} \mathrm{Cl} \mathrm{N} 4$ \\
Peso molecular & 222,7 \\
Ponto de fusão & $101,0-103,3$ \\
Coeficiente de partição $\left(\mathrm{K}_{\mathrm{ow}}\right)$ & $0,80\left(25^{\circ} \mathrm{C}\right)$ \\
Solubilidade em água & $4200 \mathrm{mg} / \mathrm{L}\left(25^{\circ} \mathrm{C}\right)$ \\
Pressão de vapor $\left(25^{\circ} \mathrm{C}\right)$ & $<1 \times 10^{-6} \mathrm{~Pa}$ \\
\hline
\end{tabular}

Fonte: Tomlin (1994)

Comercialmente é encontrado com os nomes Mospilam e Saurus. É utilizado para o controle de pragas das ordens Hemiptera (especialmente afídeos), Thysanoptera e Lepidoptera, das seguintes culturas: algodão, batata, tomate, trigo, feijão, melancia, café e citros (ANVISA, 2001; Tomlin, 1994).

Para a cultura do tomate, seu registro apresenta limite máximo de resíduo (ou tolerância) de $0,5 \mathrm{mg} / \mathrm{kg}$, e o intervalo de segurança (período de carência) de 3 dias (ANVISA, 2001).

O modo de ação do acetamiprid é baseado em estudos eletrofisiológicos e bioquímicos. Ele age como agonista da acetilcolina, receptor do sistema nervoso central do inseto (Matsuda \& Takahashi, 1996; Yamamoto, 1996). E, segundo Horowitz et al. (1998), tem, ainda, excelente propriedade sistêmica e translaminar, e alto poder residual.

De acordo com a ANVISA (2001), a classe toxicológica do acetamiprid é a III, ou seja, é um produto moderadamente tóxico. E, suas propriedades toxicológicas apresentam-se na Tabela 4. 
Tabela 4. Propriedades toxicológicas e ecotoxicológicas do acetamiprid.

\begin{tabular}{ccc}
\hline Fator & Sexo & Quantidade de acetamiprid \\
\hline DL50 aguda oral & machos & $217 \mathrm{mg} / \mathrm{kg}$ \\
(ratos) & fêmeas & $146 \mathrm{mg} / \mathrm{kg}$ \\
DL $_{50}$ aguda oral & machos & $198 \mathrm{mg} / \mathrm{kg}$ \\
(camundongos) & fêmeas & $184 \mathrm{mg} / \mathrm{kg}$ \\
DL50 aguda dermal & machos & $>2000 \mathrm{mg} / \mathrm{kg}$ \\
(ratos) & fêmeas & $>2000 \mathrm{mg} / \mathrm{kg}$ \\
Irritação da pele e olhos & - & Não-irritante \\
(coelhos) & & $>0,29 \mathrm{mg} / \mathrm{L}$ \\
Inalação CL50 (4 h) & machos & $>0,29 \mathrm{mg} / \mathrm{L}$ \\
(ratos) & fêmeas & negativo \\
Mutagenicidade & - & $>100 \mathrm{mg} / \mathrm{L}$ \\
(Ames teste) & - & $>100 \mathrm{mg} / \mathrm{L}$ \\
CL50 (carpa) & - &
\end{tabular}

Fonte: Tomlin (1994)

Matsuda \& Takahashi (1996)

\subsubsection{Thiamethoxam}

É um inseticida sistêmico do grupo químico dos neonicotinóides, de nome químico 3-(2-cloro-tiazol-5-ilmetil)-5-metil-[1,3,5]oxadiazinan-4-ilideno-N-nitroamina (ANVISA, 2001; SCHWARTZ et al., 2000). Sua fórmula estrutural está representada na Figura 3. 


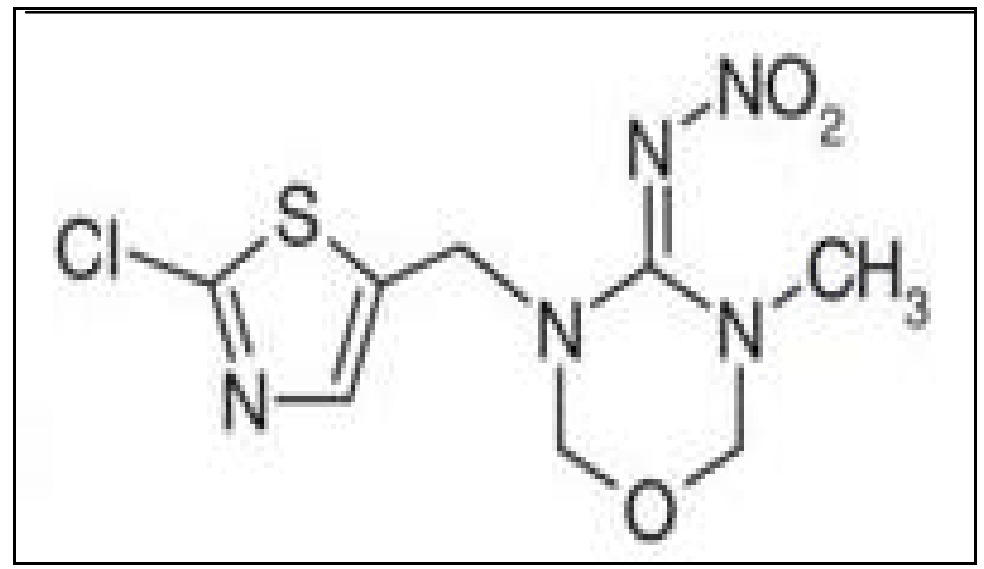

Figura 3 - Fórmula estrutural do thiamethoxam.

Os produtos comerciais do thiamethoxam são: Cruiser, Actara e Conquest, sendo utilizados para o controle de afídeos, mosca branca, tripes, cigarrinhas, entre outros. São recomendados para as seguintes culturas: melão, pepino, abobrinha, berinjela, pimentão, tomate, repolho, citros, vagem, amendoim, arroz, algodão, milho, trigo, café, cana-deaçúcar e fumo (ANVISA, 2001).

O limite máximo de resíduo (ou tolerância) do thiamethoxam para a cultura do tomate é de $1 \mathrm{mg} / \mathrm{kg}$, tanto para aplicação foliar, quanto para aplicação no solo. E, o intervalo de segurança é de 10 dias para aplicação no solo, e 3 dias para aplicação foliar (ANVISA, 2001).

Thiamethoxam apresenta modo de ação na interferência do receptor de acetilcolina do sistema nervoso do inseto, segundo Aramaki ${ }^{1}$.

\footnotetext{
${ }^{1}$ ARAMAKI, P. (NOVARTIS. São Paulo). Comunicação pessoal, 2000.
} 
Segundo o mesmo autor, na aplicação foliar bem como no tratamento de sementes, thiamethoxam é rapidamente absorvido pelas plantas. E, a quantidade de produto recuperado em folhas tratadas é entre 15 e $40 \%$ do volume aplicado.

Após a aplicação foliar e penetração nas plantas, o thiamethoxam é transportado via xilema na direção acropetal, sendo que todas as regiões abaixo da aplicação têm altas concentrações do produto, podendo haver algum acúmulo nas extremidades das folhas.

Um grande volume do ingrediente ativo é transferido da superfície para dentro da folha por processo de penetração sistêmica. Os principais processos que levam a perda de thiamethoxam depositado na superfície das folhas são a fotólise e a lavagem pelas chuvas, segundo Aramaki².

A classe toxicológica do thiamethoxam é III, sendo, portanto, um produto moderadamente tóxico. Suas propriedades toxicológicas estão representadas na Tabela 5.

Tabela 5. Propriedades físicas e químicas do thiamethoxam.

\begin{tabular}{cc}
\hline Parâmetros & Valores \\
\hline Fórmula química & $\mathrm{C}_{8} \mathrm{H}_{10} \mathrm{ClN}_{5} \mathrm{O}_{3} \mathrm{~S}$ \\
Peso molecular & 291,7 \\
Ponto de fusão & $139,1^{\circ} \mathrm{C}$ \\
Coeficiente de partição $\left(\mathrm{K}_{\mathrm{ow}}\right)$ & $0,62\left(25^{\circ} \mathrm{C}\right)$ \\
Pressão de vapor $\left(25^{\circ} \mathrm{C}\right)$ & $6,6 \times 10^{-6} \mathrm{mPa}$ \\
\hline
\end{tabular}

Fonte: www.tactri.gov.tw

Segundo Schwartz et al.(2000), citam que o thiamethoxam sofre degradação sob condições fotolíticas.

${ }^{2}$ ARAMAKI, P. (NOVARTIS, São Paulo). Comunicação pessoal, 2000. 


\subsection{Mosca branca}

\subsubsection{Histórico}

As moscas brancas pertencem à ordem Hemiptera, subordem Sternorryncha e família Aleyrodidae, a qual é subdividida em duas subfamílias: Aleyrodicinae e Aleyrodinae. Já foram descritas cerca de 1200 espécies de mosca branca, entretanto, acredita-se que esse número seja muito maior. A distribuição das espécies ocorre em função da latitude, concentrando-se a grande maioria (724 espécies) nos trópicos (BinkMoenen \& Mound, 1990).

A mosca branca, Bemisia tabaci, foi descrita pela primeira vez por Gennadius em 1889, na Grécia, em cultura de fumo (Cock, 1986). Essa espécie é cosmopolita, acreditando-se que seu centro de origem seja a Ásia e, talvez, o Paquistão (Brown \& Bird, 1992; Brown et al., 1995).

De 1926 a 1981, B. tabaci foi constatada em diversos locais do mundo, como praga esporádica e secundária, mas importante como vetor de doenças nas regiões tropicais e subtropicais (Costa, 1976; Villas-Boas et al., 1997).

No Brasil, os surtos de B. tabaci foram verificados em plantações de algodão, em 1968, no norte do Paraná e, em soja, algodão e feijão, no norte do Paraná e na região sul do Estado de São Paulo, na safra de 1972/73 (Costa et al., 1973).

Os surtos populacionais de B. tabaci em hortaliças e ornamentais intensificaramse a partir de 1991, no Estado de São Paulo, nos municípios de Paulínia, Holambra, Jaguariúna e Arthur Nogueira, destacando-se, entre as culturas mais atacadas, o tomate, a berinjela e a abóbora (Lourenção \& Nagai, 1994).

No Brasil, a mosca branca ocorre, atualmente, nos Estados de São Paulo, Minas Gerais, Goiás, Paraná, Distrito Federal, Bahia, Pernambuco, Ceará, Mato Grosso do Sul, Rio Grande do Norte, Tocantins e Rio de Janeiro (Villas-Boas et al., 1997).

Os principais hospedeiros da mosca branca são: cucurbitáceas (abobrinha, melancia, melão e chuchu), solanáceas (tomate, berinjela, pimentão, fumo, pimenta e 
jiló), brássicas (brócolis e repolho), leguminosas (feijão, feijão-vagem), algodão, mandioca, alface e quiabo, além de plantas ornamentais, daninhas e silvestres (Mello, 1992; Villas-Boas et al., 1997). O número de plantas hospedeiras de Bemisia spp. tem aumentado com o decorrer do tempo, o que tem sido atribuído, entre outras razões, ao uso de práticas agrícolas de monocultivo irrigado (Brown et al., 1995).

\subsubsection{Danos}

A mosca branca, considerada uma das principais pragas do tomateiro, causa danos diretos pela sucção da seiva, injeção de toxinas e liberação de "honeydew" na superfície das folhas, levando à formação de fumagina, e indiretamente pela transmissão de doenças viróticas (Ohnesorge \& Rapp, 1986; Yokomi et al., 1990).

Segundo Markham et al. (1994), a mosca branca, B. tabaci é uma praga polífaga, de ocorrência geral em temperaturas tropicais, subtropicais e de casa-de-vegetação, além de regiões frias, e pode rapidamente transmitir viroses incluindo gemini- e viroses como clostero- (Wisler et al., 1998).

Costa et al. (1975) relataram pela primeira vez uma doença causada por geminivírus em tomate, estando sua transmissão associada à mosca branca.

O controle de insetos transmissores de viroses geralmente é difícil, pois os vetores são muito móveis e pequenos, o que dificulta a prevenção da colonização das culturas (Antignus et al., 1998).

Costa et al. (1993) observaram que a alimentação contínua de 20 adultos de $B$. tabaci não foi suficiente para induzir danos, o que ocorreu, no entanto, com apenas duas ninfas por planta durante 14 dias: a severidade dos danos foi crescente com o número de ninfas.

A importância da mosca branca em cultivos de expressão econômica tornou-se crescente a partir da década de 80 devido à intensificação das atividades agrícolas em monocultivos irrigados e à intensa utilização de defensivos químicos e fertilizantes (Brown et al., 1995). 
As moscas brancas são insetos vetores de geminivirus, podendo causar danos graves, mesmo quando presentes em baixa população. Quando a população é baixa, os prejuízos são relacionados apenas à transmissão de viroses; se a população atinge um nível elevado, além da atividade vetora, podem atuar como praga (Costa et al., 1973). Embora outros fitopatógenos possam ser transmitidos por esse inseto, os vírus são os causadores dos maiores problemas (Costa, 1976).

Em plantas de tomate, a mosca branca causa danos diretos pela sucção da seiva, o que provoca o amadurecimento irregular dos frutos, afetando a qualidade comercial do produto, e favorece o aparecimento de fumagina. Além desse problema, pode ocorrer, nessa cultura, a transmissão da geminivirose denominada "tomato yellow leaf curl virus", cujos sintomas nas plantas são mosqueamento amarelo pálido de folhas novas e enrolamento das demais folhas (Schuster et al., 1990).

\subsubsection{Controle}

A experiência sugere que várias técnicas devem ser empregadas para o controle da mosca branca, e que muitas vezes, um só método de controle não é suficiente.

Pode-se utilizar do controle biológico (parasitóides, predadores, patógenos), práticas culturais (barreiras vegetais, plástico, armadilhas), variedades resistentes, atividades de pós-colheita, rotação de culturas e controle químico (Alpízar, 1993; Gravena et al., 1984; La Torre, 1990).

\subsubsection{Controle químico}

Muitos inseticidas têm sido utilizados para o controle da mosca branca em várias culturas. Estes compreendem vários grupos químicos, como organofosforados, carbamatos, piretróides e outros grupos de introdução recente. Para a cultura do tomate, estes mesmos grupos químicos podem ser utilizados (Alpízar, 1992). 
Planes \& Carrero (1994) citam os seguintes inseticidas para o controle da mosca branca, para plantações em geral: ciflutrina, deltametrina, fenpropatrin, fenvalerato e metamidofós. Para tomate, os mesmos autores citam os seguintes defensivos: cipermetrina e permetrina.

Nakano et al. (2002) realizaram um ensaio onde thiamethoxam foi aplicado em pulverização e na forma de sachê, no solo, na cultura do feijão. Ambos tratamentos apresentaram boa eficiência, porém, os autores citam a preferência pela aplicação via sachê, por ser menos agressiva ao meio ambiente.

Horowitz et al. (1998) citam que inseticidas como imidacloprid e acetamiprid têm excelente propriedades sistêmicas e translaminar, e alto efeito residual, e por isso são utilizados para o controle de insetos sugadores, como afídeos, cigarrinhas e mosca branca, na cultura do algodão.

Martins \& Nishimura (2002) confirmaram a eficácia dos produtos pymetrozine e thiamethoxam no controle de ninfas de mosca branca na cultura do tomate, onde os índices de eficiência foram superiores a $85 \%$.

Villas Bôas et al. (2002) comprovaram que inseticidas neonicotinóides (imidacloprid, thiacloprid e thiamethoxam) foram eficientes para o controle da mosca branca (Bemisia argentifolii) nas fases de ovo, ninfa, pupa e adulto, na cultura do tomate, e que 1/100 da dose comercial dos produtos testados apresentaram controle de $50 \%$ da população. 


\section{MATERIAL E MÉTODOS}

\subsection{Caracterização e condução dos experimentos de campo}

Dois experimentos de campo foram instalados nas dependências do Departamento de Entomologia, Fitopatologia e Zoologia Agrícola da Escola Superior de Agricultura "Luiz de Queiroz" - ESALQ/USP, no município de Piracicaba, Estado de São Paulo, no período de março a maio de 2001 e de maio a julho de 2002.

A instalação do primeiro experimento ocorreu no transplante das mudas de tomate em 9 de março de 2001, sendo utilizado o cultivar Santa Clara, com espaçamento de 1 metro entre linhas e 0,30 metro entre plantas. O segundo experimento ocorreu com o transplante das mudas no dia 4 de maio de 2002, onde foi utilizado novamente o cultivar Santa Clara, e os espaçamentos foram os mesmos do primeiro experimento.

Os tratos culturais foram realizados conforme exigências para a cultura do tomate, como: adubação, controle de doenças e plantas daninhas e irrigação.

No primeiro experimento a irrigação foi feita com auxílio de regadores e mangueiras, enquanto que no segundo experimento, a irrigação foi permanente, com o auxílio de mangueiras onde a irrigação foi feita por gotejamento.

Os experimentos apresentaram delineamento estatístico em blocos ao acaso com 7 tratamentos e 4 repetições. Cada parcela constou de 6 plantas. O experimento foi alocado de forma que as parcelas se situaram uma ao lado da outra no sentido da declividade do terreno.

Os produtos aplicados foram: Actara 250 WG , na formulação grânulos dispersíveis em água, que contém $250 \mathrm{~g}$ de thiamethoxam por litro de produto comercial, 
e Mospilan, na formulação pó solúvel, que contém 200 g de acetamiprid por litro de produto comercial.

Foram realizados três tipos de aplicações, descritas a seguir:

a) aplicação em forma de "band-aid": consiste na mistura do inseticida a um gel seco, colocando-se estes produtos em um saquinho de papel $(2 \times 2 \mathrm{~cm})$ e preso a uma fita adesiva. Este "band-aid" foi colocado no colo das plantas no momento do transplante. À medida que o gel contido no "band-aid" era molhado, havia uma liberação gradual do inseticida, sendo absorvido pela planta. A função do gel ao receber água, é a de aumentar seu volume em 5 mil vezes, protegendo o ingrediente ativo por mais tempo, evitando a possível depredação pelos colóides do solo, oferecendo, teoricamente, um residual maior no controle de pragas.

b) aplicação em forma de sachê: onde o inseticida foi misturado com o gel seco e acondicionado em sachês confeccionados de papel $(2 \times 2 \mathrm{~cm})$. Estes foram colocados junto à raiz das mudas por ocasião do plantio. Da mesma forma que o "band-aid", o sachê proporciona uma liberação gradual do inseticida, que entrou em contato com o solo, para posterior absorção por parte da planta, já contido no gel.

c) aplicação convencional: ou seja, a pulverização normal dos inseticidas.

Os tratamentos utilizados foram os seguintes:

1) Thiamethoxam ("band-aid") - 0,08 g/band-aid 25\% (na muda, ao redor do colo)

2) Acetamiprid ("band-aid") - 0,08 g/band-aid 20\% (na muda, ao redor do colo)

3) Thiamethoxam (sachê) - 0,08 g/sachê $25 \%$ (no solo, na cova de plantio)

4) Acetamiprid (sachê) - 0,08 g/sachê 20\% (no solo, na cova de plantio)

5) Thiamethoxam (convencional) - $50 \mathrm{~g}$ i.a./ha

6) Acetamiprid (convencional) - $50 \mathrm{~g}$ i.a./ha

7) Testemunha. 
As aplicações convencionais, em número de oito, foram realizadas com pulverizador costal marca Jacto de 20 litros de capacidade, equipado com bico cônico, gastando, em média, 800 litros de calda inseticida por hectare.

\subsection{Amostragens}

Foi realizada uma única amostragem 60 e 75 dias após o transplante das mudas, para o primeiro e segundo experimentos, respectivamente, tendo como objetivo verificar a ocorrência de resíduos dos inseticidas thiamethoxam e acetamiprid nos frutos e folhas de tomate, e na ocorrência de pragas na área, verificar o controle destas por parte dos tratamentos.

As amostras foram colhidas ao acaso, sendo sua retirada da planta realizada através do pedúnculo, para evitar contato com as mãos. Foram coletados 10 frutos (aproximadamente $1 \mathrm{~kg}$ de frutos) por parcela. Os frutos coletados estavam em início de maturação e foram acondicionados em sacos plásticos e transportados imediatamente para o Laboratório de Análises de Resíduos de Pesticidas do Departamento de Entomologia, Fitopatologia e Zoologia Agrícola, da Escola Superior de Agricultura "Luiz de Queiroz"- ESALQ/USP.

Para amostragem das folhas, foram coletadas aproximadamente 200 gramas por parcela, retiradas manualmente pelo pecíolo e acondicionadas em sacos plásticos, sendo imediatamente enviadas para o laboratório.

\subsection{Avaliação de controle de pragas e sintomas de viroses}

Para o segundo experimento, avaliou-se o controle de mosca branca (Bemisia tabaci biótipo B) que ocorreu na área. Não foi avaliado o controle no primeiro experimento devido à não ocorrência de pragas na área. 
Foram realizadas avaliações semanais, onde contou-se o número de ninfas e adultos da praga, coletados no terço médio das plantas e da parte inferior das folhas, em cinco plantas por tratamento. Foram realizadas avaliações visuais de sintomas de viroses nas folhas.

\subsection{Descrição do método de análise de resíduos de acetamiprid em frutos de tomateiro (Nippon Soda CO., 1996)}

\subsubsection{Princípio do método}

O método analítico consiste na extração dos resíduos de acetamiprid com metanol; a limpeza do extrato é inicialmente feita em partição líquido-líquido com hexano e solução aquosa de $\mathrm{NaCl}$, segue-se nova partição em diclorometano, esta seguida de coluna cromatográfica de florisil, sendo a eluição procedida com um mistura de acetona + hexano. A determinação quantitativa é feita por técnica de cromatografia em fase gasosa, usando-se cromatógrafo equipado com detector de captura de elétrons ( $\mu$-ECD, $\mathrm{Ni}^{63}$ pulsante).

\subsubsection{Procedimento analítico}

\subsubsection{Aparelhos/Equipamentos}

- cromatógrafo de gás, HP, modelo 6890, equipado com detector de captura de elétrons $\left(\mu-\mathrm{ECD}, \mathrm{Ni}^{63}\right.$ pulsante);

- chemstation, HP, modelo Kayak XA;

- coluna cromatográfica megabore HP-608, 30 m comprimento, diâmetro 0,53 mm e 0,5 $\mu \mathrm{m}$ espessura do filme; 
- triturador Ultra-turrax, Heidolph, modelo DIA.900;

- evaporador rotativo a vácuo, Büchi, modelo R-142 (rotavapor);

- bomba de vácuo, Primar, modelo 141;

- evaporador TurboVap LV, Zymark, modelo LV;

- purificador de água Milli-Q, Millipore, modelo Academic;

- balança analítica, Mettler, modelo H10;

- balança analítica, Sartorius, modelo Basic;

- dispenser EM, Hirschmann 5-30;

- pipetador de graduação regulável Pipetman, Gilson P 10 mL;

- ultra-som, Mini-som;

\subsubsection{Reagentes}

- acetona, p.a., Mallinckrodt, destilada em destilador de vidro;

- hexano, p.a., Mallinckrodt, destilado em destilador de vidro;

- metanol, EM Science, OmniSolv;

- diclorometano, p.a., Mallinckrodt, destilado em destilador de vidro;

- água Milli-Q;

- $\mathrm{NaCl}$, p.a., Mallinckrodt;

- $\mathrm{Na}_{2} \mathrm{SO}_{4}$, anidro granulado QM;

- Florisil 60-100 mesh, Mallinckrodt;

- Celite 545, Merck;

- padrão analítico de acetamiprid.

\subsubsection{Vidrarias e outros materiais}

- micro-seringa, $10 \mu \mathrm{l}$, Hamilton; 
- frascos de vidro com tampa rosqueável de 100 mL, Duran-Schott;

- $\quad$ provetas graduadas, 25 e $50 \mathrm{~mL}$;

- $\quad$ pipetas graduadas, 1,5 e $10 \mathrm{~mL}$;

- balões de fundo chato, $250 \mathrm{~mL}$, Pyrex 4100, 24/40;

- kitassatos, $500 \mathrm{~mL}$, Pyrex 5340;

- funis de separação, squib, 500 mL, Pyrex 6404

- funis de Büchner, Chiarotti 03-90;

- funis de vidro, Pyrex;

- erlenmayers, 250 mL, Pyrex 5020;

- beakers, $150 \mathrm{~mL}$, Pyrex 1000;

- colunas cromatográfica, vidro, 15 x $300 \mathrm{~mm}$, provida de torneira de teflon e placa de porosidade grosseira;

- vidros âmbar, $15 \mathrm{~mL}$ com tampa rosqueável;

- $\quad$ tubos de centrífuga, 15 mL, Pyrex 8080;

- espátulas.

\subsubsection{Marcha analítica}

\subsubsection{Preparo das soluções padrão}

Inicialmente foram preparadas soluções estoque de acetamiprid em acetona. Para tanto, o padrão analítico é pesado em balança analítica de precisão, e o material solubilizado no citado solvente, de modo a fornecer concentração exata de $1 \mathrm{mg} / \mathrm{mL}$ (solução estoque). As soluções padrão para estudos de fortificações e injeções no sistema cromatográfico GLC, são preparadas a prater de solução estoque com as diluições feitas, igualmente, em acetona. 


\subsubsection{Fortificações}

\section{- $\quad$ Nível 0,05 mg/kg (ppm)}

Foi preparado, inicialmente, solução de acetamiprid na concentração de 1,0 $\mu \mathrm{g} / \mathrm{mL}$, obtida a partir da solução estoque, descrita anteriormente, com diluições feitas em acetona. Juntou-se $1 \mathrm{~mL}$ da solução assim obtida em subamostras de $10 \mathrm{~g}$ cada uma do substrato obtido de tomates (frutos) triturados e homogeneizados, sabidamente nunca anteriormente contaminados.

\section{- $\quad$ Nível 0,5 mg/kg (ppm)}

Inicialmente, foi preparado uma solução de acetamiprid na concentração de 10 $\mu \mathrm{g} / \mathrm{mL}$, obtida a partir de solução estoque, descrita anteriormente, com diluições feitas em acetona. Juntou-se $1 \mathrm{~mL}$ da solução assim obtida em subamostras de $10 \mathrm{~g}$ cada uma do substrato obtido de tomates (frutos) triturados e homogeneizados, sabidamente nunca anteriormente contaminados.

\subsubsection{Extração}

I. Foi pesado $10 \mathrm{~g}$ da amostra homogeneizada, colocada em tubo Duran-Schott, onde se juntou $50 \mathrm{~mL}$ de metanol e foi homogeneizado em Ultra-turrax por 5 minutos.

II. O homogeneizado foi filtrado através de funil de Büchner, forrado ao fundo com papel de filtro e com uma camada de Celite $545(1-2 \mathrm{~cm})$, com auxílio de vácuo. Os conteúdos do tubo e do funil foram lavados mais duas vezes com $25 \mathrm{~mL}$ de metanol. Os filtrados foram combinados em funil de separação de $500 \mathrm{~mL}$. 


\subsubsection{Limpeza}

a) Partição líquido-líquido:

I. Foi adicionado $100 \mathrm{~mL}$ de uma solução aquosa $5 \%$ de $\mathrm{NaCl}$ ao filtrado.

II. Foi adicionado $100 \mathrm{~mL}$ de hexano e agitado por 10 minutos, e a fase orgânica foi descartada.

III. A fase aquosa foi extraída duas vezes com $100 \mathrm{~mL}$ de diclorometano, recolhendo cada uma destas frações em balão redondo de fundo chato, previamente filtradas com cerca de $50 \mathrm{~g}$ de $\mathrm{Na}_{2} \mathrm{SO}_{4}$, suspensos em funil de vidro. $\mathrm{O}$ funil de $\mathrm{Na}_{2} \mathrm{SO}_{4}$ foi lavado com mais $25 \mathrm{~mL}$ de diclorometano e esta fração foi recolhida igualmente no balão redondo.

IV. Foi adicionado $1 \mathrm{~g}$ de florisil ao extrato e evaporado o solvente em rotavapor em banho de $35-40^{\circ} \mathrm{C}$ até $2-5 \mathrm{~mL}$. O solvente remanescente foi evaporado com auxílio de vácuo.

b) Coluna cromatográfica

I. Foi preparada uma coluna cromatográfica de florisil, tomando o adsorvente de estufa a $130-140^{\circ} \mathrm{C}$, mantido em ativação, e subsequentemente, deixado esfriar por sobre a bancada, transferindo $9 \mathrm{~g}$ dele por meio de um "slurry" em hexano para coluna cromatográfica de 15 x $300 \mathrm{~mm}$.

II. $\mathrm{O}$ extrato contido no balão de fundo chato foi, então, transferido para a coluna com duas lavagens de $10 \mathrm{~mL}$ cada uma, de uma amostra de acetona mais hexano $(2 / 8, v / v)$, descartando-se os eluados.

III. Passou-se $130 \mathrm{~mL}$ da mistura acima citada pela coluna e novamente, foi descartado o eluado. 
IV. Finalmente, os resíduos de acetamiprid foram eluídos da coluna com $120 \mathrm{~mL}$ de uma mistura acetona mais hexano $(1 / 1, \mathrm{v} / \mathrm{v})$ e coletado todo o eluado em um outro balão de fundo chato de $250 \mathrm{~mL}$.

V. O eluado foi evaporado em rotavapor em banho-maria de $55-60^{\circ} \mathrm{C}$ até cerca de 2-5 mL; o solvente remanescente foi evaporado com auxílio de vácuo.

\subsubsection{Determinação quantitativa}

I. As paredes internas do balão redondo proveniente de solvente remanescente acima citado, foram lavadas três vezes, com $5 \mathrm{~mL}$ de acetona cada vez, recolhendo as lavagens em tubo de centrífuga graduado.

II. O extrato foi concentrado no TurboVap LV até volume adequado.

III. Foram injetadas alíquotas no cromatógrafo com programação de temperatura, modo "splitless".

IV. Condições de operação do cromatógrafo:

Temperaturas:

Injetor $\quad 230^{\circ} \mathrm{C}$

Coluna $50^{\circ} \mathrm{C}$ segura $1 \mathrm{~min}$.;

$240^{\circ} \mathrm{C} @ 40^{\circ} \mathrm{C} / \mathrm{min}$. Segura zero min.;

$300^{\circ} \mathrm{C} @ 25^{\circ} \mathrm{C} / \mathrm{min}$. Segura 3 min.;

Detector $\quad 320^{\circ} \mathrm{C}$

Fluxo dos gases:

$\mathrm{H}_{2}: 5 \mathrm{~mL} / \mathrm{min}$. (arraste)

$\mathrm{N}_{2}: 30 \mathrm{~mL} / \mathrm{min}$. (make up)

Tempo de retenção: 8 min. $40 \mathrm{~s}$ 


\subsubsection{Cálculo dos resíduos}

Os resíduos são calculados por comparação direta com o padrão (padronização externa), baseados nas massas do padrão analítico e das amostras.

$$
\mathrm{Ppm}=\mathrm{mg} / \mathrm{kg}=\frac{\mathrm{mp} 1 \times \mathrm{mam}}{\mathrm{Mp} 2 \times \mathrm{Mam}} \text {, onde: }
$$

mp1 = massa injetada do padrão em ng;

mam = massa da substance da amsotra, em ng, obtida por processamento do cromatograma no workstation;

mp2 = massa da substance no padrão, em ng, obtida igualmente, por processamento do cromatograma igualmente, pelo workstation;

Mam = massa da amostra injetada em mg.

\subsection{Descrição do método de análise de resíduos de acetamiprid em folhas de tomateiro}

O método de análise de resíduos foi em tudo muito semelhante ao método anteriormente descrito para frutos.

\subsubsection{Reagentes}

Como descrito no intem 3.4.1. 


\subsubsection{Aparelhos/ Equipamentos}

Como descrito no item 3.4.2.

\subsubsection{Vidrarias e outros materiais}

Como descrito no item 3.4.3.

\subsubsection{Marcha analítica}

Como descrito no item 3.4.4.

\subsection{Descrição do método de análise de resíduos de hiamethoxam em frutos de tomateiro (Novartis, 1998)}

\subsubsection{Princípio do método}

O método analítico consiste na extração dos resíduos totais de thiamethoxam e seu metabólito CGA 322704, com mistura de metanol + água; a limpeza do extrato é inicialmente feita em partição líquido-líquido entre o extrato aquoso e diclorometano; segue-se coluna cromatográfica de sílica-gel, sendo a eluição procedida com acetonitrila; finalmente, a limpeza do extrato é concluída por meio de cromatografia de permeação em gel(GPC), utilizando-se como fase móvel mistura de acetona/ciclohexano (2/1). A determinação quantitativa é feita por técnica de cromatografia líquida HPLC, usando-se cromatógrafo equipado com detector de UV visível. 


\subsubsection{Procedimento analítico}

\subsubsection{Aparelhos/Equipamentos}

- cromatógrafo líquido, Gilson equipado com detector de UV visível;

- software Gilson UniPoint;

- injetor/coletor de frações, Gilson, modelo 215;

- coluna LiChrospher $100 \mathrm{RP}-18$, diâmetro $3 \mathrm{~mm}$ x $125 \mathrm{~mm}$ e $5 \mu \mathrm{m}$ de tamanho de partícula;

- coluna Plgel, $300 \mathrm{~mm}$ comprimento, diâmetro 7,5 mm, $5 \mu \mathrm{m}$ de tamanho de partícula e $100 \AA$ A de poro;

- coluna Plgel, $300 \mathrm{~mm}$ comprimento, diâmetro 7,5 mm, $5 \mu \mathrm{m}$ de tamanho de partícula e $50 \AA ̊$ de poro;

- moinho elétrico Sire Cutter;

- evaporador/concentrador, Zymark, TurboVap-LV;

- mesa agitadora, Marconi;

- centrífuga, Revan, Ciclo CI;

- bomba de vácuo, Primar, modelo 141;

- purificador de água Milli-Q, Millipore, modelo Academic;

- balança analítica, Mettler, modelo H10;

- balança analítica, Sartorius, modelo Basic;

- $\quad$ pipetador de graduação regulável Pipetman, Gilson P 10 mL;

\subsubsection{Solventes/Reagentes}

- acetona, p.a., Mallinckrodt, destilada em destilador de vidro;

- diclorometano, nanograde, Mallinckrodt; 
- metanol, AR, Mallinckrodt;

- metanol, HPLC, Mallinckrodt;

- acetonitrila, HPLC, Mallinckrodt;

- ciclohexano, AR, Mallinckrodt;

- água Milli-Q;

- $\quad$ sílica-gel, Merck, 230-400 mesh;

- $\mathrm{Na}_{2} \mathrm{SO}_{4}$, anidro, granulado, $\mathrm{QM}$;

- sílica-gel, dessecante azul;

- Celite 545;

- padrão analítico de thiamethoxam;

- padrão analítico de CGA 322704 (metabólito)

\subsubsection{Vidrarias e outros materiais}

- tubos Schott, $100 \mathrm{~mL}$, tampa rosqueável;

- balões volumétricos, 100 mL, Corning-Pyrex 5642;

- kitazatos, $500 \mathrm{~mL}$, Corning-Pyrex 5340;

- funis de Büchner, $90 \mathrm{~mm} \phi$, Chiaroti 03-90

- provetas graduadas, $25,50,100$ e $250 \mathrm{~mL}$;

- pipetas graduadas, 1,5 e $10 \mathrm{~mL}$;

- pipeta volumétrica, $25 \mathrm{~mL}$;

- beakers, $150 \mathrm{~mL}$, Corning-Pyrex 1000;

- vidros âmbar, $15 \mathrm{~mL}$ com tampa rosqueável;

- tubos de centrífuga, $15 \mathrm{~mL}$, Corning-Pyrex 8080;

- tubos de centrífuga, $50 \mathrm{~mL}$, Corning 430829;

- seringas hipodérmicas, polietileno, $\mathrm{BD}, 5 \mathrm{~mL}$ e $10 \mathrm{~mL}$;

- membrana filtrante, HV, Millex,0,45 ì m poro x 13 mm diâmetro;

- papéis de filtro, analítico; 
- peras de borracha;

- espátulas.

\subsubsection{Marcha analítica}

\subsubsection{Preparo das soluções}

Inicialmente, foram preparadas soluções estoque de thiamethoxam em metanol. Para tanto, os padrões analíticos são pesados em balança analítica de precisão, e o material solubilizado no citado solvente, de modo a fornecer concentração exata de 0,2 $\mathrm{mg} / \mathrm{mL}$. As soluções padrão, para injeções no sistema cromatográfico HPLC, são preparadas a partir das soluções estoque com as diluições feitas em água deionizada.

\subsubsection{Fortificações}

\section{- Nível 0,02 mg/kg (ppm)}

Inicialmente foram preparadas soluções de thiamethoxam na concentração de 0,2 $\mu \mathrm{g} / \mathrm{mL}$, obtidas a partir das soluções estoque, descritas anteriormente, com diluições feitas em metanol. Adicionourse $1 \mathrm{~mL}$ de cada solução, assim obtida, em subamostras de 10 g cada uma de substrato (tomate), obtido de frutos sabidamente nunca anteriormente contaminados. 


\section{- $\quad$ Nível 0,2 mg/kg (ppm)}

Foram preparadas, inicialmente, soluções de thiamethoxam na concentração de 2 $\mu \mathrm{g} / \mathrm{mL}$, obitdas a partir das soluções estoque, descritas anteriormente, com diluições feitas em metanol. Adicionou-se $1 \mathrm{~mL}$ de cada solução, assim obtida, em subamostras de 10 g cada uma do substrato (tomate), obtido de frutos sabidamente nunca anteriormente contaminados.

\subsubsection{Extração}

I. Foi pesado $10 \mathrm{~g}$ da amostra homogeneizada, colocada em tubo Schott, onde adicionou-se $50 \mathrm{~mL}$ de uma mistura de metanol + água $(1 / 1, \mathrm{v} / \mathrm{v})$ e foi agitado em mesa agitadora durante uma hora a 140 ciclos/minuto.

II. $\quad \mathrm{O}$ extrato foi filtrado, através de funil de Büchner, forrado ao fundo com papel d efiltro recoberto por uma camada de Celite 545, para um kitassato com auxílio de vácuo. Os conteúdos do tubo Schott e os do funil foram lavados com mais $30 \mathrm{~mL}$ da mistura.

III. O extrato foi transferido para balão volumétrico de $100 \mathrm{~mL}$ e completado o volume até a marca com a mistura dos solventes de extração.

IV. Foi retirada uma alíquota de $20 \mathrm{~mL}$ (correspondente a $2 \mathrm{~g}$ do material) e foi transferida para um tubo de polietileno de $50 \mathrm{~mL}$.

\subsubsection{Limpeza}

I. Adicionou-se $20 \mathrm{~mL}$ de diclorometano e agiotu-se vigorosamente durante um minuto, e foi centrifugado por três minutos para melhor separação das fases. 
II. A fase orgânica inferior foi recolhida, com auxílio de pipeta volumétrica de 25 $\mathrm{mL}$, em outro tubo de $50 \mathrm{~mL}$. A fase aquosa foi re-extraída com mais $20 \mathrm{~mL}$ de diclorometano, repetindo as operações descritas.

III. O extrato foi evaporado até secura no evaporador TurboVap-LV a $40^{\circ} \mathrm{C}$ com auxílio de ar movente, fornecido por compressor, previamente seco $\mathrm{m}$ filtro de sílica-gel dessecante azul.

IV. Foi preparada coluna cromatográfica de sílica-gel, adicionand-se $2 \mathrm{~g}$ do adsorvente a uma seringa hipodérmica de polietileno de $10 \mathrm{~mL}$ e $0,5 \mathrm{~g}$ de $\mathrm{Na}_{2} \mathrm{SO}_{4}$ ao topo da coluna; esta foi condicionada com $5 \mathrm{~mL}$ de uma solução ciclohexano/acetato de etila $(1 / 1, \mathrm{v} / \mathrm{v})$.

V. Os resíduos provenientes de III. foram dissolvidos com $3 \times 2 \mathrm{~mL}$ da solução de ciclohexano/acetato de etila $(1 / 1, \mathrm{v} / \mathrm{v})$ e introduzido na coluna. Foi eluído com 20 $\mathrm{mL}$ da solução ciclohexano/acetato de etila (1/1, v/v), e descartado e eluado.

VI. Foi passado $5 \mathrm{~mL}$ de acetato de etila pela coluna, e descartado o eluado.

VII. Finalmente, os resíduos de thiamethoxam foram eluídos da coluna de sílica-gel com $13 \mathrm{~mL}$ de acetonitrila, e coletado o eluado em tubo de centrífuga de $15 \mathrm{~mL}$.

VIII. O extrato foi evaporado até secura no TurboVap-LV a $40^{\circ} \mathrm{C}$ com auxílio de ar movente, fornecido por compressor, previamente seco em filtro de sílica-gel dessecante azul.

IX. Os resíduos provenientes de VIII. foram dissolvidos em $1 \mathrm{~mL}$ de uma solução acetona/ciclohexano $(2 / 1, \mathrm{v} / \mathrm{v})$ e transferidos para vidros apropriados com tampa rosqueável e septo teflon, e feita a limpeza técnica de cromatografia de permeação em gel (GPC), usando-se como fase móvel a mesma mistura de solventes (acetona/ciclohexano), com fluxo de $1 \mathrm{~mL} / \mathrm{min}$., desprezando-se os eluados durante os 11,5 minutos iniciais e coletando a fração em eluição nos 1,5 minutos subsequentes.

X. Foi evaporado até secura no TurboVap-LV a $40^{\circ} \mathrm{C}$, com auxílio de ar movente, previamente seco em filtro de sílica-gel dessecante azul. 


\subsubsection{Determinação quantitativa}

I. Os resíduos provenientes de $\mathrm{X}$. foram dissolvidos em volume exato de $2 \mathrm{~mL}$ com água destilada e deionizada. $\mathrm{O}$ extrato foi ressuspendido em seringa hipodérmica, $\mathrm{BD}, 5 \mathrm{~mL}$.

II. Foi filtrado através de membrana filtrante Millex para vials próprios para uso no cromatógrafo.

III. Condições de operação do cromatógrafo:

$\begin{array}{ll}\text { Eluentes: } & \text { A: água } \\ & \text { B: metanol } \\ \text { Gradiente: } & 73 \% \mathrm{~A} / 27 \% \mathrm{~B} \text {, zero minuto, } \\ & 73 \% \mathrm{~A} / 27 \% \mathrm{~B}, 3 \text { minutos } 30 \text { segundos, } \\ & 55 \% \mathrm{~A} / 45 \% \mathrm{~B}, 8 \text { minutos } 30 \text { segundos, } \\ & 10 \% \mathrm{~A} / 90 \% \mathrm{~B}, 10 \text { minutos } 30 \text { segundos, } \\ & 10 \% \mathrm{~A} / 90 \% \mathrm{~B}, 11 \text { minutos } 30 \text { segundos, } \\ & 73 \% \mathrm{~A} / 27 \% \mathrm{~B}, 13 \text { minutos } 30 \text { segundos, } \\ & 73 \% \mathrm{~A} / 27 \% \mathrm{~B}, 18 \text { minutos } 30 \text { segundos, }\end{array}$

Fluxo: $\quad 0,5 \mathrm{~mL} / \mathrm{min}$.

Volume injetado: $\quad 20,0 \mu \mathrm{L}$

Comprimentos de onda: $\quad 0,0 \mathrm{~min}: 255 \mathrm{~nm}$

$7 \mathrm{~min}: 270 \mathrm{~nm}$

Temperatura da coluna: $\quad 40^{\circ} \mathrm{C}$

Range: $\quad 1 \mathrm{mAU}$ 
Tempo de retenção: 5 minutos 40 segundos

\subsection{Análise dos dados}

Foi utilizado o programa SANEST - Sistema de Análise Estatística - para o cálculo das tabelas de mortalidade de insetos. 


\section{RESULTADOS E DISCUSSÂO}

\subsection{Resíduos de acetamiprid em frutos - Experimento I}

Os resultados obtidos nas análises de resíduos de acetamiprid em frutos provenientes de plantas de tomate tratadas à campo, do primeiro experimento (realizado em 2001), estão apresentados na Tabela 6.

Tabela 6. Resíduos de acetamiprid em frutos de tomate (Experimento I)

\begin{tabular}{cc}
\hline Tratamentos/ tipo de aplicação & Quantidade de acetamiprid (mg/kg) \\
\hline Testemunha & - \\
Acetamiprid / band-aid & $<0,05$ \\
Acetamiprid / sachê & $<0,05$ \\
Acetamiprid / pulverização & 0,05 \\
\hline
\end{tabular}

No Laboratório de Análise de Resíduos de Pesticidas da ESALQ/USP, foi estabelecido o limite de quantificação do método analítico empregado em $0,05 \mathrm{mg} / \mathrm{kg}$ para frutos, o que representa um valor 10 vezes abaixo do limite máximo de resíduos (LMR) do inseticida em frutos de tomate $(0,5 \mathrm{mg} / \mathrm{kg})$, de acordo com a Agência Nacional de Vigilância Sanitária - ANVISA (ANVISA, 2001).

De acordo com a Tabela 6, somente o tratamento onde o acetamiprid foi aplicado em pulverização apresentou resíduo de $0,05 \mathrm{mg} / \mathrm{kg}$. Porém, este nível de resíduo está abaixo do LMR aceitável pela ANVISA. 
O intervalo de segurança (ou período de carência), que segundo Martinez (1984), é o intervalo de tempo entre a última aplicação do inseticida e a colheita ou comercialização do vegetal, para que os resíduos existentes estejam dentro dos limites estabelecidos pela Organização Mundial de Saúde. Este período foi respeitado, ou seja, a colheita dos frutos ocorreu num período superior a três dias da aplicação (via pulverização), que é o período de carência para o acetamiprid.

\subsection{Resíduos de acetamiprid em folhas - Experimento I}

Os resultados das análises de acetamiprid em folhas de tomate, do primeiro experimento, estão apresentados na Tabela 7.

Tabela 7. Resíduos de acetamiprid em folhas de tomate (Experimento I).

\begin{tabular}{cc}
\hline Tratamentos/ tipo de aplicação & Quantidade de acetamiprid (mg/kg) \\
\hline Testemunha & - \\
Acetamiprid / band-aid & 0,06 \\
Acetamiprid / sachê & $<0,05$ \\
Acetamiprid / pulverização & 0,4 \\
\hline
\end{tabular}

O limite de quantificação estabelecido para folhas de tomate foi de $0,05 \mathrm{mg} / \mathrm{kg}$, assim como o limite de quantificação para frutos.

Para folhas de tomate, o inseticida acetamiprid não apresenta estudos para limite máximo de resíduos, de acordo com a ANVISA.

De acordo com a Tabela 7, todos os tratamentos, com exceção da testemunha, apresentaram resíduo de acetamiprid, o que é útil, pois as folhas estariam "protegidas" contra o ataque de pragas que poderiam ser controladas pelo acetamiprid.

$\mathrm{O}$ acetamiprid aplicado em pulverização foi o tratamento que apresentou o maior índice de resíduo. Comparando o índice de resíduo dos frutos e folhas onde o produto foi 
aplicado em pulverização, pode-se notar que nas folhas este índice foi superior, fato este de acordo com Dupuis (1975), que relata a maior exposição das folhas à pulverização.

Quanto às aplicações do acetamiprid nas formas de "band-aid" e sachê, ambos os tratamentos apresentaram resíduos, apesar de estarem em menor quantidade que na aplicação via pulverização. Novamente, de acordo com Dupuis (1975), a quantidade de resíduos nas folhas é maior que nos frutos, relatado como a influência da morfologia e fisiologia da planta sobre os resíduos encontrados nas diversas partes da mesma.

\subsection{Residuos de thiamthoxam em frutos - Experimento I}

Os resultados obtidos nas análises de resíduos de thiamethoxam em frutos provenientes de plantas de tomate tratadas à campo, do primeiro experimento (realizado em 2001), estão apresentados na Tabela 8.

Tabela 8. Resíduos de thiamethoxam e seu metabólito CGA 322704, em frutos de tomate (Experimento I).

\begin{tabular}{ccc}
\hline Tratamentos/ tipo de aplicação & $\begin{array}{c}\text { Quantidade de } \\
\text { thiamethoxam }(\mathbf{m g} / \mathbf{k g})\end{array}$ & $\begin{array}{c}\text { Quantidade de } \\
\text { CGA 322704 } \\
\text { (mg/kg) }\end{array}$ \\
\hline Testemunha & - & - \\
Thiamethoxam / band-aid & $<0,02$ & $<0,02$ \\
Thiamethoxam / sachê & $<0,02$ & $<0,02$ \\
Thiamethoxam / pulverização & $<0,02$ & $<0,02$ \\
\hline
\end{tabular}

Foi estabelecido o limite de quantificação do método analítico empregado em $0,02 \mathrm{mg} / \mathrm{kg}$ para frutos, o que representa um valor 50 vezes menor que o limite máximo de resíduos do thiamethoxam (do ingrediente ativo e seu metabólito) em frutos de tomate (1 mg/kg), de acordo com a ANVISA (ANVISA, 2001). 
De acordo com a Tabela 8, todos os tratamentos apresentaram resíduos de thiamethoxam e seu metabólito CGA 322704 abaixo do limite máximo de resíduos estabelecido pela ANVISA. A colheita dos frutos respeitou o intervalo de segurança, que para o thiamethoxam é de 3 dias para tratamento foliar (pulverização) e de 10 dias para aplicação no solo ('band-aid”' e sachê).

\subsection{Resíduos de thiamethoxam em folhas - Experimento I}

Os resultados das análises de thiamethoxam e seu metabólito CGA 322704 em folhas de tomate, do primeiro experimento, estão apresentados na Tabela 9.

Tabela 9. Resíduos de thiamethoxam e seu metabólito CGA 322704 em folhas de tomate (Experimento I).

\begin{tabular}{ccc}
\hline Tratamentos/ tipo de aplicação & $\begin{array}{c}\text { Quantidade de } \\
\text { thiamethoxam (mg/kg) }\end{array}$ & $\begin{array}{c}\text { Quantidade de } \\
\text { CGA 322704 } \\
\text { (mg/kg) }\end{array}$ \\
\hline Testemunha & - & - \\
Thiamethoxam / band-aid & $<0,02$ & 0,01 \\
Thiamethoxam / sachê & 0,06 & 0,05 \\
Thiamethoxam / pulverização & 0,35 & 0,45 \\
\hline
\end{tabular}

O Imite de quantificação estabelecido para folhas de tomate foi de $0,02 \mathrm{mg} / \mathrm{kg}$, assim como o limite de quantificação para frutos.

Para folhas de tomate, o inseticida thiamethoxam não apresenta estudos para limite máximo de resíduos, de acordo com a ANVISA. 
Na Tabela 9, pode-se observar que somente o tratamento onde o thiamethoxam foi aplicado na forma de "band-aid", não apresentou resíduo. Os demais apresentaram resíduos do thiamenthoxam (ingrediente ativo) e seu metabólito (CGA 322704).

Novamente, como nos tratamentos com o inseticida acetamiprid, o thiamethoxam aplicado em pulverização, apresentou maior índice de resíduo. E, comparando-se os de resíduos em frutos e folhas, estes apresentam maiores índices, o que novamente, pode-se relatar a hipótese de Dupuis (1975), onde a morfologia e fisiologia da planta influencia na deposição de resíduos em suas partes.

\subsection{Resíduos de acetamiprid em frutos - Experimento II}

Os resultados obtidos nas análises de resíduos de acetamiprid em frutos provenientes de plantas de tomate tratadas à campo, do primeiro experimento (realizado em 2002), estão apresentados na Tabela 10.

Tabela 10. Resíduos de acetamiprid em frutos de tomate (Experimento II).

\begin{tabular}{cc}
\hline Tratamentos/ tipo de aplicação & Quantidade de acetamiprid (mg/kg) \\
\hline Testemunha & - \\
Acetamiprid / band-aid & $<0,05$ \\
Acetamiprid / sachê & $<0,05$ \\
Acetamiprid / pulverização & $<0,05$ \\
\hline
\end{tabular}

O limite de quantificação estabelecido para acetamiprid em frutos de tomate foi de $0,05 \mathrm{mg} / \mathrm{kg}$, sendo o limite máximo de resíduos estabelecido pela ANVISA como 0,5 $\mathrm{mg} / \mathrm{kg}$ (ANVISA, 2001).

De acordo com a Tabela 10, todos os tratamentos apresentaram índices de resíduos abaixo do limite de quantificação $(0,05 \mathrm{mg} / \mathrm{kg})$. 


\subsection{Resíduos de acetamiprid em folhas - Experimento II}

Os resultados das análises de acetamiprid em folhas de tomate, do segundo experimento, estão apresentados na Tabela 11.

Tabela 11. Resíduos de acetamiprid em folhas de tomate (Experimento II).

\begin{tabular}{cc}
\hline Tratamentos/ tipo de aplicação & Quantidade de acetamiprid (mg/kg) \\
\hline Testemunha & - \\
Acetamiprid / band-aid & $<0,05$ \\
Acetamiprid / sachê & $<0,05$ \\
Acetamiprid / pulverização & $<0,05$ \\
\hline
\end{tabular}

O limite de quantificação estabelecido para folhas de tomate foi de $0,05 \mathrm{mg} / \mathrm{kg}$, assim como o limite de quantificação para frutos.

$\mathrm{Na}$ análise das folhas de tomate onde o acetamiprid foi aplicado, todos os tratamentos apresentaram índice de resíduo abaixo do limite de quantificação.

Com esses resultados, as folhas estão "desprotegidas" do ataque da praga suscetível ao inseticida, no caso, a mosca branca.

\subsection{Resíduos de thiamethoxam em frutos - Experimento II}

Os resultados obtidos nas análises de resíduos de thiamethoxam em frutos provenientes de plantas de tomate tratadas à campo, do segundo experimento (realizado em 2002), estão apresentados na Tabela 12. 
Tabela 12. Resíduos de thiamethoxam e seu metabólito CGA 322704, em frutos de tomate (Experimento II).

\begin{tabular}{ccc}
\hline Tratamentos/ tipo de aplicação & $\begin{array}{c}\text { Quantidade de } \\
\text { thiamethoxam }(\mathbf{m g} / \mathbf{k g})\end{array}$ & $\begin{array}{c}\text { Quantidade de } \\
\text { CGA 322704 } \\
\text { (mg/kg) }\end{array}$ \\
\hline Testemunha & - & - \\
Thiamethoxam / band-aid & $<0,02$ & $<0,02$ \\
Thiamethoxam / sachê & $<0,02$ & $<0,02$ \\
Thiamethoxam / pulverização & $<0,02$ & $<0,02$ \\
\hline
\end{tabular}

Foi estabelecido o limite de quantificação do método analítico empregado em 0,02 $\mathrm{mg} / \mathrm{kg}$ de thiamethoxam (ingrediente ativo e seu metabólito - CGA 322704) para frutos, o que representa um valor 50 vezes menor que o limite máximo de resíduos do thiamethoxam em frutos de tomate ( $1 \mathrm{mg} / \mathrm{kg}$ ), de acordo com a ANVISA (2001).

De acordo com a Tabela 12, todos os tratamentos apresentaram indíces de resíduos de thiamethoxam e seu metabólito abaixo do limite de quantificação e abaixo do limite máximo de resíduo estabelecido pela ANVISA para frutos de tomate.

\subsection{Residuos de thiamethoxam em folhas - Experimento II}

Os resultados das análises de thiamethoxam e seu metabólito CGA 322704 em folhas de tomate, do segundo experimento, estão apresentados na Tabela 13. 
Tabela 13. Resíduos de thiamethoxam e seu metabólito CGA 322704 em folhas de tomate (Experimento II).

\begin{tabular}{ccc}
\hline $\begin{array}{c}\text { Tratamentos/ tipo de } \\
\text { aplicação }\end{array}$ & $\begin{array}{c}\text { Quantidade de } \\
\text { thiamethoxam }(\mathbf{m g} / \mathbf{k g})\end{array}$ & $\begin{array}{c}\text { Quantidade de } \\
\text { CGA 322704 } \\
\text { (mg/kg) }\end{array}$ \\
\hline Testemunha & - & - \\
Thiamethoxam / band-aid & $<0,02$ & $<0,02$ \\
Thiamethoxam / sachê & $<0,02$ & $<0,02$ \\
Thiamethoxam / pulverização & $<0,02$ & $<0,02$ \\
\hline
\end{tabular}

O limite de quantificação estabelecido para folhas de tomate foi de $0,02 \mathrm{mg} / \mathrm{kg}$, assim como o limite de quantificação para frutos.

Para folhas de tomate, o inseticida thiamethoxam não apresenta estudos para limite máximo de resíduos, de acordo com a ANVISA.

Novamente, todos os tratamentos apresentaram índices de resíduos abaixo do limite de quantificação e, com isso, as folhas não estão protegidas do ataque da mosca branca.

\subsection{Avaliação do controle de pragas}

\subsubsection{Experimento I}

Neste experimento, realizado em 2001, não ocorreram pragas que fossem suscetíveis aos inseticidas acetamiprid e thiamethoxam, como afídeos, cigarrinhas e moscas brancas, o que impossibilitou a avaliação de eficiência dos produtos testados. 


\subsubsection{Experimento II}

Neste experimento, realizado em 2002, a área apresentava infestação natural de mosca branca, o que possibilitou a avaliação de controle e eficiência dos inseticidas testados.

As porcentagens de eficiência foram calculadas pela Fórmula de Abbott (ABBOTT, 1925), onde:

$$
\% \mathrm{Ef}=\frac{\% \text { mort trat }-\% \text { mort test }}{100-\% \text { mort test }} \times 100
$$

A Tabela 14 representa os números médios de ninfas e adultos de mosca branca em folhas de tomate, por tratamento, bem como as porcentagens de eficiência, na primeira avaliação realizada em 29 de maio de 2002, aos 25 dias após o transplante das mudas no campo.

Está também representado o Teste de Tukey, onde médias seguidas pela mesma letra não diferem entre si ao nível de $5 \%$ de probabilidade.

Observando a Tabela 14, verifica-se que nesta avaliação somente o tratamento Mospilan aplicado na forma de "band-aid", apresentou controle superior a $80 \%$, e o tratamento Mospilan aplicado na forma de sachê controle de 62,8\%. Os demais tratamentos apresentaram número de insetos vivos semelhante ou superior à testemunha, porém, de acordo com o Teste de Tukey, todos os tratamentos assemelharam-se à testemunha. 
Tabela 14. Número médio de adultos e ninfas de mosca branca vivas, por tratamento, porcentagem de eficiência, 25 dias após o transplante das mudas de tomate. Piracicaba, 2002.

\begin{tabular}{ccc}
\hline Tratamentos & Número de insetos vivos & Eficiência (\%) \\
\hline Testemunha & $35 \mathrm{a}^{*}$ & - \\
Mospilan (band-aid) & $5 \mathrm{a}$ & 85,7 \\
Actara (band-aid) & $35 \mathrm{a}$ & - \\
Mospilan (sachê) & $13 \mathrm{a}$ & 62,8 \\
Actara (sachê) & $39 \mathrm{a}$ & - \\
Mospilan (pulverização) & $47 \mathrm{a}$ & - \\
Actara (pulverização) & $41 \mathrm{a}$ & - \\
CV (\%) & 63,48 & \\
\hline
\end{tabular}

* Médias seguidas pela mesma letra não diferem entre si pelo teste de Tukey $(\mathrm{P}>0,05)$

Na Tabela 15 estão representados os números de insetos vivos e suas porcentagens de controle, no dia 5 de junho de 2002, aos 32 dias após o transplante das mudas.

De acordo com a Tabela 15, todos os tratamentos apresentaram porcentagem de eficiência abaixo de $80 \%$, com níveis baixos de controle para a referida praga.

O tratamento Actara aplicado na forma de sachê, apresentou número de insetos vivos superior à testemunha.

Todos os tratamentos apresentaram controle semelhante, de acordo com a análise estatística. 
Tabela 15. Número médio de adultos e ninfas de mosca branca vivas, por tratamento, porcentagem de eficiência, 32 dias após o transplante das mudas de tomate. Piracicaba, 2002.

\begin{tabular}{ccc}
\hline Tratamentos & Número de insetos vivos & Eficiência (\%) \\
\hline Testemunha & $27 \mathrm{a}^{*}$ & - \\
Mospilan (band-aid) & $12 \mathrm{a}$ & 55,5 \\
Actara (band-aid) & $16 \mathrm{a}$ & 40,7 \\
Mospilan (sachê) & $15 \mathrm{a}$ & 44,4 \\
Actara (sachê) & $35 \mathrm{a}$ & - \\
Mospilan (pulverização) & $13 \mathrm{a}$ & 51,8 \\
Actara (pulverização) & $18 \mathrm{a}$ & 33,3 \\
CV (\%) & 61,83 & \\
\hline
\end{tabular}

* Médias seguidas pela mesma letra não diferem entre si pelo teste de Tukey $(\mathrm{P}>0,05)$

A Tabela 16 apresenta os números de moscas brancas vivas e suas porcentagens de controle aos 40 dias após o transplante das mudas, no dia 13 de junho de 2002.

Nesta Tabela, pode-se observar que a Testemunha apresenta baixo índice de infestação e, os demais tratamentos não apresentaram bons resultados de eficiência. Somente o tratamento Mospilan aplicado na forma de sachê e em pulverização apresentaram índice de eficiência mais alto, porém, ainda bem abaixo de $80 \%$. Tais valores não foram considerados, tendo em vista o baixo número de insetos no tratamento Testemunha. 
Tabela 16. Número médio de adultos e ninfas de mosca branca vivas, por tratamento, porcentagem de eficiência, 40 dias após o transplante das mudas de tomate. Piracicaba, 2002.

\begin{tabular}{ccc}
\hline Tratamentos & Número de insetos vivos & Eficiência (\%) \\
\hline Testemunha & $7 \mathrm{a}^{*}$ & - \\
Mospilan (band-aid) & $6 \mathrm{a}$ & 14,3 \\
Actara (band-aid) & $12 \mathrm{a}$ & - \\
Mospilan (sachê) & $4 \mathrm{a}$ & 42,8 \\
Actara (sachê) & $17 \mathrm{a}$ & - \\
Mospilan (pulverização) & $3 \mathrm{a}$ & 57,1 \\
Actara (pulverização) & $8 \mathrm{a}$ & - \\
CV (\%) & 48,07 & \\
\hline
\end{tabular}

* Médias seguidas pela mesma letra não diferem entre si pelo teste de Tukey $(\mathrm{P}>0,05)$

A Tabela 17 apresenta o número de insetos vivos por tratamento e sua porcentagem de controle, aos 43 dias após o transplante das mudas no campo, dia 16 de junho de 2002. Nela, pode-se observar que os melhores índices de controle foram obtidos com os tratamentos Mospilan e Actara, ambos aplicados em pulverização, sendo este último próximo de $80 \%$. Somente o tratamento Actara aplicado na forma de "bandaid" apresentou número de insetos vivos superior à Testemunha. Os demais tratamentos apresentaram porcentagens de eficiência superior à $30 \%$.

Todos os tratamentos assemelharam-se à testemunha, de acordo com o Teste de Tukey. 
Tabela 17. Número médio de adultos e ninfas de mosca branca vivas, por tratamento, porcentagem de eficiência, 43 dias após o transplante das mudas de tomate. Piracicaba, 2002.

\begin{tabular}{ccc}
\hline Tratamentos & Número de insetos vivos & Eficiência (\%) \\
\hline Testemunha & $13 \mathrm{a}^{*}$ & - \\
Mospilan (band-aid) & $9 \mathrm{a}$ & 30,7 \\
Actara (band-aid) & $14 \mathrm{a}$ & - \\
Mospilan (sachê) & $6 \mathrm{a}$ & 53,8 \\
Actara (sachê) & $7 \mathrm{a}$ & 46,1 \\
Mospilan (pulverização) & $4 \mathrm{a}$ & 69,2 \\
Actara (pulverização) & $3 \mathrm{a}$ & 76,9 \\
CV (\%) & 46,40 & \\
\hline
\end{tabular}

* Médias seguidas pela mesma letra não diferem entre si pelo teste de Tukey $(\mathrm{P}>0,05)$

A última avaliação foi realizada aos 54 dias após o transplante das mudas, como mostra a Tabela 18. Nela estão representados os números de insetos vivos por tratamento e suas respectivas porcentagens de mortalidade.

Pode-se observar na Tabela 18, que todos os tratamentos apresentaram número de insetos vivos igual ou superior à Testemunha, o que impossibilitou o cálculo da porcentagem de eficiência. E, nenhum tratamento diferiu da testemunha, segundo o Teste de Tukey ao nível de 5\% de probabilidade. 
Tabela 18. Número médio de adultos e ninfas de mosca branca vivas, por tratamento, porcentagem de eficiência, 54 dias após o transplante das mudas de tomate. Piracicaba, 2002.

\begin{tabular}{ccc}
\hline Tratamentos & Número de insetos vivos & Eficiência (\%) \\
\hline Testemunha & $5 \mathrm{a}^{*}$ & - \\
Mospilan (band-aid) & $16 \mathrm{a}$ & - \\
Actara (band-aid) & $8 \mathrm{a}$ & - \\
Mospilan (sachê) & $13 \mathrm{a}$ & - \\
Actara (sachê) & $17 \mathrm{a}$ & - \\
Mospilan (pulverização) & $5 \mathrm{a}$ & - \\
Actara (pulverização) & $8 \mathrm{a}$ & \\
CV (\%) & 35,23 & \\
\hline
\end{tabular}

* Médias seguidas pela mesma letra não diferem entre si pelo teste de Tukey $(\mathrm{P}>0,05)$

A Figura 4 apresenta os índices de eficiência dos tratamentos comparando todas as avaliações realizadas durante o experimento.

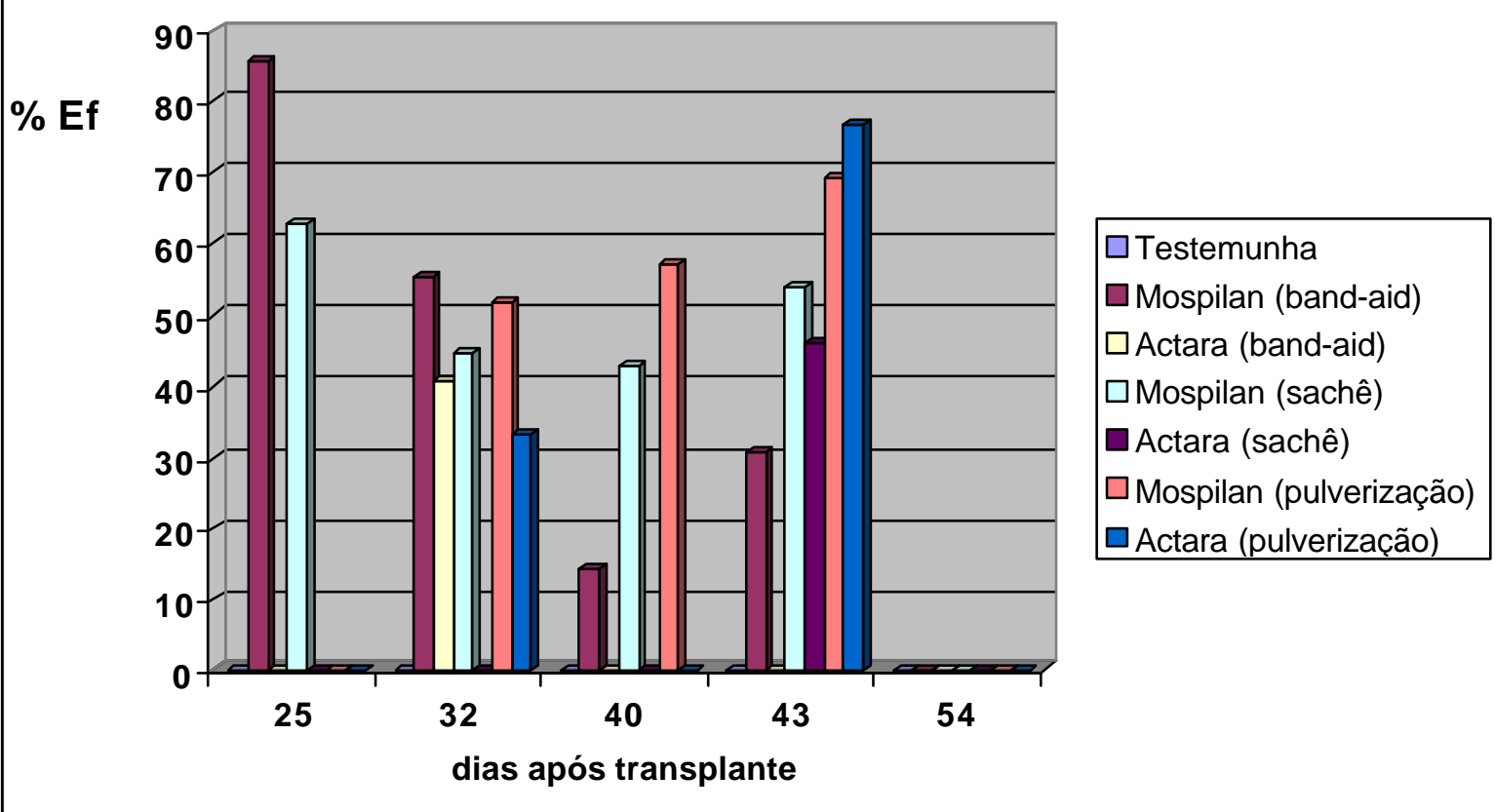

Figura 4 - Eficiência dos tratamentos visando o controle da mosca branca na cultura do tomate, em todas as avaliações realizadas durante o experimento. 
De acordo com a Figura 4, pode-se observar que inicialmente, aos 25 dias após o transplante das mudas, os tratamentos que apresentaram melhor eficiência foram Mospilan aplicado na forma de "band-aid" e na forma de sachê.

Aos 32 dias após o transplante, todos os tratamentos apresentaram eficiência semelhante, com destaque para os tratamentos Mospilan aplicado na forma de "bandaid" e em pulverização. Com 40 e 43 dias do transplante, Mospilan aplicado em pulverização apresentou um dos maiores índices de eficiência, acompanhado dos tratamentos Mospilan aplicado na forma de sachê e Actara aplicado em pulverização. Aos 54 dias do transplante, nenhum tratamento apresentou índice de eficiência.

Os dados conflitam com alguns dados da literatura, como por exemplo, Villas Boas et al. (2002), que citam que o thiamethoxam apresenta alto índice de controle para Bemisia tabaci biótipo B , quando aplicado em pulverização, na cultura do tomate. E, Martins \& Nishimura (2002) citam que thiamethoxam (Actara 250 WG) aplicado em pulverização, apresentou controle superior a $85 \%$ da mosca branca, na cultura do tomate.

\subsection{Quantidade de ingrediente ativo aplicado por hectare}

\subsubsection{Thiamethoxam ("band-aid")}

Cada planta de tomate recebeu o equivalente a $0,08 \mathrm{~g}$ p.c../ha de thiamethoxam a $25 \%$, e sua área correspondente no campo é igual a $0,3 \mathrm{~m}^{2}$.

Com esses dados, pode-se dizer que:

$$
\begin{aligned}
& 0,3 \mathrm{~m}^{2} \\
& 10.000 \mathrm{~m}^{2} \quad \text {--------- } \mathrm{x}=33.333 \text { plantas }
\end{aligned}
$$

A quantidade do thiamethoxam (produto comercial) por hectare é equivalente a: 33.333 plantas x 0,08 g p.c. $=2666,64$ g p.c. $/$ ha 
A quantidade de ingrediente ativo por hectare é igual a:

$2.666,64$ g p.c./ha $x 25 \%$ do i.a. $=666,66$ g i.a. $/$ ha

\subsubsection{Acetamiprid (“band-aid”)}

Cada planta de tomate recebeu o equivalente a 0,08 g p.c../ha de acetamiprid a $20 \%$, e sua área correspondente no campo é igual a $0,3 \mathrm{~m}^{2}$.

Com esses dados, pode-se dizer que:

$$
\begin{aligned}
& 0,3 \mathrm{~m}^{2} \\
& 10.000 \mathrm{~m}^{2} \quad \text {---------- } \mathrm{x}=33.333 \text { plantas }
\end{aligned}
$$

A quantidade do acetamiprid (produto comercial) por hectare é equivalente a:

33.333 plantas x 0,08 g p.c. $=2666,64$ g p.c. $/$ ha

A quantidade de ingrediente ativo por hectare é igual a:

$2.666,64$ g p.c./ha $x 20 \%$ do i.a. $=533,33$ g i.a. $/$ ha

\subsubsection{Thiamethoxam (sachê)}

Cada planta de tomate recebeu o equivalente a $0,08 \mathrm{~g}$ p.c../ha de thiamethoxam a $25 \%$, e sua área correspondente no campo é igual a $0,3 \mathrm{~m}^{2}$.

Com esses dados, pode-se dizer que:

$$
\begin{aligned}
& 0,3 \mathrm{~m}^{2} \\
& 10.000 \mathrm{~m}^{2} \quad \text {--------- } \mathrm{x}=33.333 \text { plantas }
\end{aligned}
$$

A quantidade do thiamethoxam (produto comercial) por hectare é equivalente a:

33.333 plantas x 0,08 g p.c. $=2666,64$ g p.c. $/$ ha

A quantidade de ingrediente ativo por hectare é igual a:

$2.666,64$ g p.c./ha $x 25 \%$ do i.a. $=666,66$ g i.a. $/$ ha 


\subsubsection{Acetamiprid (sachê)}

Cada planta de tomate recebeu o equivalente a 0,08 g p.c./ha de acetamiprid a $20 \%$, e sua área correspondente no campo é igual a $0,3 \mathrm{~m}^{2}$.

Com esses dados, pode-se dizer que:

$$
\begin{aligned}
& 0,3 \mathrm{~m}^{2} \\
& 10.000 \mathrm{~m}^{2} \quad \text {--------- } \mathrm{x}=33.333 \text { plantas }
\end{aligned}
$$

A quantidade do acetamiprid (produto comercial) por hectare é equivalente a:

33.333 plantas x 0,08 g p.c. $=2666,64$ g p.c. $/$ ha

A quantidade de ingrediente ativo por hectare é igual a:

$2.666,64$ g p.c./ha $x 20 \%$ do i.a. $=533,33$ g i.a. $/$ ha

\subsubsection{Thiamethoxam (pulverização)}

Para a pulverização, utilizou-se o equivalente a $50 \mathrm{~g}$ do ingrediente ativo por hectare em cada aplicação. Foram realizadas 8 aplicações durante o ciclo da cultura. A quantidade de ingrediente ativo total correspondeu a:

$50 \mathrm{~g}$ i.a./ha $\times$ 8 aplicações $=400 \mathrm{~g}$ i.a./ha

\subsubsection{Acetamiprid (pulverização)}

A pulverização com acetamiprid foi realizada assim como o thiamethoxam, onde foram aplicados $50 \mathrm{~g}$ do ingrediente ativo por hectare por aplicação, num total de 8 aplicações. E, novamente:

$50 \mathrm{~g}$ i.a./ha $x 8$ aplicações $=400 \mathrm{~g}$ i.a./ha

Pode-se observar que a quantidade de ingrediente ativo aplicado por hectare foi menor nas pulverizações, em relação às aplicações na forma de sache e "band-aid". 


\subsubsection{Correlação entre a quantidade de ingrediente ativo e porcentagem de eficiência}

A Tabela 19 mostra a correlação entre a quantidade de ingrediente ativo dos produtos por hectare com suas respectivas porcentagens de eficiência média dos 32 e 43 dias após o transplante das mudas no campo. Nela, pode-se notar que os tratamentos aplicados em pulverização apresentaram os maiores índices médios de eficiência. Isto ocorreu devido à maior quantidade de resíduo que ainda permaneceu no substrato, ou seja, havia maior quantidade de produto na planta, já que a pulverização foi realizada semanalmente, até 15 dias antes da colheita dos frutos para análise dos resíduos.

Esses valores eram esperados, pois nas aplicações na forma de "band-aid" e sachê, mesmo sendo aplicados em quantidades iniciais maiores que na pulverização, estes ocorreram somente no plantio, e foi sendo degradado lentamente por fatores físicos e químicos da planta e do solo, até atingir valores baixos e não proporcionar mais uma porcentagem de eficiência semelhante à pulverização, que foi periódica, longa e mais próxima da análise de resíduo.

Tabela 19. Correlação entre as quantidades de ingrediente ativo por tratamento e suas respectivas porcentagens de eficiência, média dos 32 e 43 dias após o transplante das mudas. Piracicaba, 2002.

\begin{tabular}{ccc}
\hline Tratamentos & $\begin{array}{c}\text { Quantidade de produto } \\
\text { (g i.a./ha) }\end{array}$ & $\begin{array}{c}\text { Eficiência } \\
(\mathbf{\%})\end{array}$ \\
\hline Actara ("band-aid") & 666,66 & 20,35 \\
Mospilan ("band-aid") & 533,33 & 43,10 \\
Actara (sachê) & 666,66 & 23,05 \\
Mospilan (sachê) & 533,33 & 49,10 \\
Actara (pulverização) & 400,00 & 55,10 \\
Mospilan (pulverização) & 400,00 & 60,50 \\
\hline
\end{tabular}




\subsection{Avaliação de sintomas de viroses}

Não foram detectados sintomas de viroses nas plantas de tomate avaliadas.

\subsection{Vantagens das aplicações nas formas de "band-aid" e sachê}

Pode-se observar, de acordo com os resultados, que as aplicações na forma de "band-aid" e sachê apresentam menor risco para o aplicador, já que este está menos exposto ao inseticida se comparado à pulverização. Isto evita acidentes de trabalho, como intoxicações, ocasionados por aplicação de defensivos que, segundo Trapé (1993), vem aumentando gradativamente devido à falta de preparo para a utilização da tecnologia do seu uso. Em estudo realizado por Vicente et al. (1998), observaram-se dados sobre intoxicações em culturas de tomate em Apiaí (SP) onde, em 1996, o índice de casos era de 133 para cada 1000 habitantes.

Outro ponto importante é a ação sobre os inimigos naturais, já que nas aplicações em pulverização, o produto cai diretamente sobre os insetos, prejudicando, assim, a sobrevivência de insetos benéficos para a cultura. Isto é verificado, segundo Baptista (1999), para insetos polinizadores e, como recomendação, deve-se aplicar inseticidas seletivos para inimigos naturais. Porém, se aplicado nas formas de "band-aid" e sachê, o risco de mortalidade é menor.

Os defensivos podem entrar na atmosfera por diferentes vias, principalmente da deriva das pulverizações. E, de acordo com Baptista (1999), durante a aplicação, embora a maior parte seja depositada no alvo pretendido, uma porção se move com a deriva, sendo levada a alguns quilômetros de distância. Outro problema é a fotodecomposição do defensivo que, exposto diretamente ao sol, é degradado e suas propriedades físicoquímicas são perdidas.

A chuva também pode ser um fator para a perda do produto aplicado, ou seja, se este for pulverizado e ocorrer chuva logo após, o serviço fica comprometido. Estes e 
outros problemas podem ser amenizados com as aplicações realizadas nestes experimentos, onde os produtos são aplicados diretamente no solo, durante o plantio das mudas, evitando, assim, parte da poluição ambiental, a fotodecomposição do produto e sua perda por lavagem da chuva.

Poderia se imaginar que as aplicações de inseticidas via solo podem permitir escorrimento pelas chuvas, poluindo nascentes, ou rios. No presente caso, tanto o sachê como o "band-aid" são constituídos com gel, que na presença de umidade, retém as partículas de inseticidas, tornando-as disponíveis às raízes que, pela proximidade e força de pressão, retêm seus ativos para colocar à disposição das plantas.

Deve-se ressaltar, ainda, que estes tipos de aplicações não requerem equipamentos especiais, como pulverizadores, tratores, equipamentos de proteção individuais sofisticados, sendo necessário somente luvas, máscara e botas. E isto reduz o custo das aplicações, pois não necessitando de equipamentos especiais, não há o desgaste destes como um todo e de suas partes, sem levar em consideração operações com máquinas que também podem causar acidentes aos operadores. 


\section{CONCLUSÕES}

A análise dos resultados obtidos nas condições experimentais utilizadas, permitiu concluir que:

1 - De acordo com a análise de resíduos, todos os tratamentos apresentaram o limite máximo de resíduo (LMR) abaixo do índice estabelecido pela Agência Nacional de Vigilância Sanitária (ANVISA);

2 - Os melhores índices de controle foram obtidos pelos tratamentos onde o modo de aplicação utilizado foi a pulverização;

3 - As modalidades de aplicação sachê e "band-aid" apresentaram controle satisfatório da praga, com a vantagem de não poluir o meio ambiente como os tratamentos em pulverização, evitando a mortalidade de inimigos naturais benéficos para a cultura do tomate;

4 - Aplicações na forma de "band-aid" e sachê evitam a contaminação nãointencional (indireta) por parte do aplicador, ficando, este, menos exposto à resíduos dos inseticidas aplicados em pulverização. 


\section{REFERÊNCIAS BIBLIOGRÁFICAS}

ABBOTT, W.S. A method of computing the effectiveness of an insecticide. Journal of Economic Entomology, v.18, p.265-267, 1925.

AGÊNCIA NACIONAL DE VIGILÂNCIA SANITÁRIA.

http://www.anvisa.gov.br/alimentos/tox/mono/index.htm (14 dez. 2001)

ALPÍZAR, D. Apsectos basicos sobre las moscas blancas com enfasis em Bemisia tabaci y Trialeurodes vaporarorium. San Jose: Ministerio de Agricultura y Ganaderia, 1993. 23 p. (Boletín Divulgativo, 112).

ANTIGNUS, Y.; LADIPOT, M.; HADAR, D.; MESSIKA, Y.; COHEN, S. Ultravioletabsorbing screens serve as optical barriers to protect crops from virus and insect pests. Journal of Economic Entomology, v.91, n.6, p.1401-1405, 1998.

ANUÁRIO ESTATÍSTICO DO BRASIL - 1997, v.57, p.3-48, 1998.

ANUÁRIO ESTATÍ́STICO DO ESTADO DE SÃO PAULO - 1994, p.676, 1995.

ATHERTON, J.G.; RUDICH, J. The tomato crop. New York: Chapman and Hall, 1986. $661 \mathrm{p}$.

BARBOSA, S.; FRANÇA, F.H. As pragas do tomateiro e seu controle. Informe Agropecuário, v.6, n.66, p.37-40, 1980. 
BAPTISTA, G.C. Curso de proteção de plantas: toxicologia, meio ambiente e legislação. Brasília: ABEAS, 1999. 33 p.

BAPTISTA, G.C.; PARRA, J.R.P.; NAKANO, O. Controle químico. In: NAKANO, O. (Coord.). Curso de entomologia aplicada à agricultura. Piracicaba: FEALQ, 1992. p.197-217.

BAPTISTA, L.H.L.; BAPTISTA, G.C.; LONGATTI, C.E.; MANDON, L.D. Resíduos de zetacipermetrina em tomate determinados por cromatografia de gás. In: CONGRESSO BRASILEIRO DE ENTOMOLOGIA, 15., Caxambu, 1995. Resumos. Caxambu: SEB, 1995. p. 483.

BINK-MOENEM, R.M.; MOUND, L.A. Whiteflies: Diversity, byosystematics and evolutionary patterns. In: GERLING, D. (Ed.). Whiteflies: their bionomics, pests status and management. Winborne: Intercept, 1990. cap.1, p.1-12.

BRASIL. Ministério da Agricultura. Legislação federal de agrotóxicos e afins. Brasília: Ministério da Agricultura, Departamento de Defesa e Inspeção Vegetal, 1998. 184 p.

BRIOSCHI, D. Resíduos de clorotalonil em frutos e folhas de tomate de cultura estaqueada (Lycopersicon esculentum Mill.). Piracicaba, 2001. 57 p. Dissertação (Mestrado) - Escola Superior de Agricultura "Luiz de Queiroz", Universidade de São Paulo.

BROWN, J.K.; BIRD, J. Whitefly-transmitted geminiviruses and associated disorders in the Americas and Caribbean Basin. Plant Disease, v. 76, n.3, p.220-225, 1992. 
BROWN, J.K.; FROHLICH, D.R.; ROSELL, R.C. The sweetpotato or silverleaf whiteflies: biotypes of Bemisia tabaci or a species complex? Annual Review of Entomology, v.40, p.511-534, 1995.

COCK, M.J.W. (Ed.). Bemisia tabaci: a literature survey on the cotton whitefly with an annotated bibliography. Ascot: FAO;CAB, 1986. 121 p.

COSTA, A.S. Whitefly-transmitted plant diseases. Annual Review of Phytopathology, v.16, p.429-449, 1976.

COSTA, A.S.; COSTA, C.L.; SAUER, H.F.G. Surto de mosca branca em culturas do Paraná e São Paulo. Anais da Sociedade Entomológica do Brasil, v.2, n.1, p.20-30, 1973.

COSTA, A.S.; OLIVEIRA, A.R.; SILVA, D.M. Transmissão mecânica do mosaico dourado do tomateiro. In: CONGRESSO BRASILEIRO DE FITOPATOLOGIA, 8., Mossoró, 1975. Resumos. Mossoró: ABRATES, 1975. p.147.

COSTA, H.S.; ULLMAN, D.E.; JOHNSON, M.W.; TABASHNIK, B.E. Squash silverleaf symptoms induced by immature, but not adult, Bemisia tabaci. Phytopatology, v.83, n.7, p.763-766, 1993.

DUPUIS, G. Pesticide residue in citrus. In: CIBA-GEIGY AGROCHEMICALS. Citrus. Berna, 1975. v.1, p.91-98.

EBELING, W. Analysis of the basic process involved in the deposition, degradation, persistance, and effectiveness of pesticides. Residue Reviews, v.3, p.35-163, 1963. 
EVARISTO, A. Resíduos deslocáveis de metamidofós em cultura estaqueada de tomate (Lycopersicon esculentum Mill.). Piracicaba, 1994. 55 p. Dissertação (Mestrado) Escola Superior de Agricultura "Luiz de Queiroz", Universidade de São Paulo.

FERREIRA, L.H. Desenvolvimento de um novo sistema para extração com fluido supercrítico (SFE) e sua aplicação na análise de resíduos de clorotalonil em alimentos. São Carlos, 1995. 92 p. Dissertação (Mestrado) - Instituto de Química de São Carlos, Universidade de São Paulo.

FNP CONSULTORIA \& COMÉRCIO. Agrianual 1999: anuário da agricultura brasileira. São Paulo, 1999. 441 p.

FOLQUER, F. El tomate: estudio de la planta y su produccion comercial. Buenos Aires: Hemisferio Sur, 1976. 105 p.

FREEDMAN, B. Environmental ecology: the impacts of pollution and other stresses on ecosystem structure and function. San Diego: Academic Press, 1989. 424 p.

GALLO, D.; NAKANO, O.; SILVEIRA NETO, S.; CARVALHO, R.P.L.; BAPTISTA, G.C.; BERTI FILHO, E.; PARRA, J.R.P.; ZUCCHI, R.A.; ALVES, S.B.; VENDRAMIN, J.D. Manual de entomologia agrícola. São Paulo: Ceres, 1988. $649 \mathrm{p}$.

GARCIA, E.D. Segurança e saúde no trabalho rural com agrotóxicos: contribuição para uma abordagem mais abrangente. São Paulo, 1996. 232 p. Dissertação (Mestrado) Faculdade de Saúde Pública, Universidade de São Paulo. 
GRAVENA, S. Manejo integrado da mosca branca Bemisia tabaci (Gennadius, 1989) em cultivares de tomateiro de crescimento determinado, visando redução da virose do mosaico dourado. Anais da Sociedade Entomológica do Brasil, v.13, n.1, p.34-45, 1984.

GUNTHER, F.A. Inseticides residues in California citrus fruits and products. Residue Reviews, v.28, p.1-127, 1969.

HOROWITZ, A.R.; MENDELSON, Z.; WEINTRAUB, P.G.; ISHAAYA, I. Comparative toxicity of foliar and systemic applications of acetamiprid and imidacloprid against the cotton whitefly, Bemisia tabaci (Hemiptera: Aleyrodidae). Bulletin of Entomological Research, v.88, p.437-442, 1998.

INSTITUTO BRASILEIRO DE GEOGRAFIA E ESTATÍSTICA. http://www.ibge.com.br (14 dez. 2001)

JENKINS, J.A. The origin of the cultivated tomato. Economic Botany, v.2, n.4, p.379$392,1948$.

LARA, W. A tolerância tem limites. Ciência Hoje, v.4, n.22, p.63-64, 1986.

LATORRE, B.A. Plagas de las hortalizas:.manual de manejo integrado. Santiago: FAO, 1990. 380 p.

LATORRE, B.A.; APABLAZA, J.U.; VAUGHAM, M.A.; KOGAN, M.; HELFGOTT, S.; LORCA, G. Plagas de las hortalizas: manual de manejo integrado. Santiago: FAO, 1990. 520 p.

LOURENÇÃO, A.L.; NAGAI, H. Surtos populacionais de Bemisia tabaci no Estado de São Paulo. Bragantia, v.53, n.1, p.53-59, 1994. 
LYKKEN, L. Important considerations in collecting and preparing crop samples for residue analysis. Residue Reviews, v.3, p.19-34, 1963.

MARANCA, G. Tomate. São Paulo: Nobel, 1981. 158 p.

MARKHAM, P.G.; BEDFORD, I.D.; LIU, S.; PINNER, M.S. The transmission of Geminiviruses by Bemisia tabaci. Pesticide Science, v.42, p.123-128, 1994.

MARTINEZ, E. F. III curso sobre toxicologia de defensivos agrícolas. Piracicaba: ANDEF, 1984. 150p.

MARTINS, J.C.; NISHIMURA, M. Pymetrozine e thiamethoxam no controle de ninfas da mosca branca Bemisia argentifolii (Bellows \& Perring) em cultura de tomate. In: CONGRESSO BRASILEIRO DE ENTOMOLOGIA, 19., Manaus, 2002. Resumos. Manaus: SEB, 2002. p. 112.

MATSUDA, M.; TAKAHASHI, H. Mospilan® (acetamiprid, NI-25) - a new systemic insecticide. Agrochemicals Japan, n. 68, p.20-21, 1996.

MATSUMARA, F. Toxicology of ins ecticides. New York: Plenum Press, 1985. 598 p.

MINAMI, K. Tecnologia de produção. In: MINAMI, K.; FONSECA, H. (Ed.). Tomate: produção, pré-processamento e transformação agroindustrial. Piracicaba: FEALQ, 1983. p.1-39.

MINAMI, K.; HAAG, H.P. O tomateiro. 2.ed. Campinas: Fundação Cargill, 1989. 397 p. 
NAKANO, O. Controle químico das pragas da hortaliças, garantindo a alimentação do homem. Revista da Adealq, n.2, p.36-40, 1985.

NAKANO, O. As pragas das hortaliças: seu controle e o selo verde. Horticultura Brasileira, v.17, n.1, p.4-5, 1999.

NAKANO, O.; BATISTA, G.C.; SILVEIRA NETO, S. Controle químico. In: Curso de entomologia aplicada à agricultura. Piracicaba: FEALQ, 1992, p.159-196.

NAKANO, O.; FLORIM, A.C.P.; BOTTENE, A.F.C. Manejo de pragas do feijoeiro por meio de diferentes formas de aplicação do thiamethoxam. In: CONGRESSO BRASILEIRO DE ENTOMOLOGIA, 19., Manaus, 2002. Resumos. Manaus: SEB, 2002. p. 283.

NIPPON SODA CO.. Residue analytical method of insecticide NI-25 in crops. Tokyo, 1996. $12 \mathrm{p}$.

NOVARTIS CROP PROTECTION. Determination of CGA 293343 and CGA 322704 by HPLC. Basileia, 1998. 46 p.

OHNESORGE, B.; RAPP, G. Monitoring Bemisia tabaci: a review. Agriculture, Ecosystems and Environment, v.17, p.21-28, 1986.

PLANES, S.; CARRERO, J.M. Plagas del campo. Madrid: Mundi-Prensa, 1994. 550 p.

RAETANO, C.G. Resíduos de fentoato e malation em tomate (Lycopersicon esculentum Mill) determinados por cromatografia em fase gasosa. Piracicaba, 1991. 85 p. Dissertação (Mestrado) - Escola Superior de Agricultura "Luiz de Queiroz", Universidade de São Paulo. 
RAEtAnO, C.G. Resíduos de fentoato em tomate. Pesquisa Agropecuária Brasileira, v.30, n.1, p.31-36, 1995.

RICK, C.M. Fruit and pedicel characteristics derived from Galapagos tomato. Economic Botany, v.21, n.2, p.174-184, 1967.

RIGITANO, R.L.O. Persistência de resíduos de methyl parathion e quinalphos em frutos de tomate (Lycopersicon esculentum). Ciência Prática, v.6, n.1, p.63-70, 1982.

RODRIGUEZ, R.R.; RODRIGUEZ, J.M.T.; JUAN, J.A.M.S. Cultivo moderno del tomate. 2.ed. Madrid: Mundi-Prensa, 1997. 255 p.

ROUCHAUD, J.; MEYER, J.A. New trends in the studies about the metabolism of pesticides in plants. Residue Reviews, v.82, p.1-35, 1982.

SCHUSTER, D.J.; MUELLER, T.F.; KRING, J.B.; PRICE, J.F. Relationship of the sweetpotato whitefly to irregular ripening and geminiviruses in Florida. In: YOKOMI, R.K.; NARAYANAN, K.R.; SCHUSTER, D.J. (Ed.). Sweetpotato whitefly mediated vegetable disorders in Florida. Gainesville: Institute of Food and Agricultural Sciences, 1990. p.7.

SCHWARTZ, B.J.; SPARROW, F.K.; HEARD, N.E.; THEDE, B.M. Simultaneous derivatization and trapping of volatile products from aqueous photolysis of thiamethoxam insecticide. Journal of Agriculture and Food Chemistry, v.48, p.4671-4675, 2000 . 
SILVA, L.V.; GRAVENA, S.; BENVENGA, S.R.; ALLELUIA, I.B.; RODRIGUES FILHO, I.L. Manejo ecológico de pragas e doenças do tomateiro envarado (ciclo de inverno): redução das pulverizações por monitoramento. In: CONGRESSO BRASILEIRO DE ENTOMOLOGIA, 17., Rio de Janeiro, 1998. Resumos. Rio de Janeiro: SEB, 1998. p. 375.

TAIWAN AGRICULTURAL CHEMICALS AND TOXIC SUBSTANCES RESEARCH INSTITUTE.

http://www.tactri.gov.tw/htdocs/intro/pcd/thiamethoxam.pdf (02 fev. 2003)

TOMLIN, C. The pesticide manual. Farnham: British Crop Protection Council, 1994. $1341 \mathrm{p}$.

TREVIZAN, L.R.P. Resíduos de deltametrina em grãos de trigo, milho e milho pipoca e em seus produtos processados, determinados por cromatografia em fase gasosa. Piracicaba, 1998. 74 p. Dissertação (Mestrado) - Escola Superior de Agricultura "Luiz de Queiroz", Universidade de São Paulo.

VILLAREAL, R. Tomates. San Jose: IICA, 1982. 184 p.

VILLAS BOAS, G.L.; FRANÇA, F.H.; ÁVILA, A.C.; BEZERRA, I.C. Manejo integrado da mosca branca Bemisia argentifolii. Brasília: Embrapa, CNPH, 1997. 12 p. (EMBRAPA, CNPH. Circular Técnica, 9).

VILLAS BÔAS, G.L.; CASTELO BRANCO, M.; PAULO, J.A.O.; DIENER, P.S.A.; PONTES, L.A. Avaliação de inseticidas neonicotinóides no controle da mosca branca Bemisia argentifolii na cultura do tomate. In: CONGRESSO BRASILEIRO DE ENTOMOLOGIA, 19., Manaus, 2002. Resumos. Manaus: SEB, 2002. p. 139. 
WISLER, G.C.; DUFFUS, J.E.; LIU, H.Y; LI, R.H. Ecology and epidemiology of whitefly-transmitted Closteroviruses. Plant Disease, v.82, p.270-280, 1998.

YAMAMOTO, I. Neonicotinoids: mode of action and selecivity. Agrochemicals Japan, n.68, p.14-15, 1996.

YOKOMI, R.K.; HOELMER, K.A.; OSBORNE, L.S. Relationships between the sweetpotato whitefly and the squash silverleaf disorder. Phytopatology, v.80, p.895-900, 1990. 